\title{
PRMT5-Mediated RNF4 Methylation Promotes \\ Therapeutic Resistance of APL Cells to As203 by Stabilizing Oncoprotein PML-RARa
}

\section{Xinping Huang}

Peking University

\section{Yongfeng Yang}

Peking University

Dan Zhu

Peking University

Yan Zhao

Peking University

Min Wei

Peking University

Ke Li

Chinese Academy of Medical Sciences \& Peking Union Medical College

Hong-hu Zhu

Zhejiang University

xiaofeng Zheng ( $\nabla$ xiaofengz@pku.edu.cn )

Peking University

\section{Research Article}

Keywords: PRMT5, PML-RARa, RNF4, methylation, ubiquitination, acute promyelocytic leukemia

Posted Date: February 7th, 2022

DOI: https://doi.org/10.21203/rs.3.rs-1295154/v1

License: (c) (1) This work is licensed under a Creative Commons Attribution 4.0 International License. Read Full License 
PRMT5-mediated RNF4 methylation promotes therapeutic resistance of APL cells to $\mathrm{As}_{2} \mathrm{O}_{3}$ by stabilizing oncoprotein PML-RAR $\alpha$

Xinping Huang ${ }^{1,2 \#}$, Yongfeng Yang ${ }^{1,2 \#}$, Dan Zhu ${ }^{1,2}$, Yan Zhao ${ }^{1,2}$, Min Wei ${ }^{1,2}, \mathrm{Ke} \mathrm{Li}^{3}$, Hong-hu Zhu ${ }^{4}$, and Xiaofeng Zheng ${ }^{1,2, *}$

${ }^{1}$ State Key Laboratory of Protein and Plant Gene Research, School of Life Sciences, Peking University, Beijing, China. ${ }^{2}$ Department of Biochemistry and Molecular Biology, School of Life Sciences, Peking University, Beijing, China. ${ }^{3} \mathrm{NHC}$ Key Laboratory of Biotechnology of Antibiotics, Institute of Medicinal Biotechnology, Chinese Academy of Medical Sciences \& Peking Union Medical College, Beijing, China. ${ }^{4}$ Department of Hematology \& Institute of Hematology, Zhejiang Province Key Laboratory of Hematology Oncology Diagnosis and Treatment, The First Affiliated Hospital, Zhejiang University, Hangzhou, China.

"Xinping Huang \& Yongfeng Yang contributed equally to this work.

*To whom correspondence should be addressed. Xiaofeng Zheng, School of Life Sciences, Peking University, Beijing 100871, China. Tel: +86 10-6275-5712; Email: xiaofengz@pku.edu.cn

\section{Running title}

PRMT5 promotes PML-RAR $\alpha$ stability and APL progression 


\begin{abstract}
Acute promyelocytic leukemia (APL) is a hematological malignancy driven by the oncoprotein PML-RAR $\alpha$, which can be treated effectively with arsenic trioxide $\left(\mathrm{As}_{2} \mathrm{O}_{3}\right)$ or/and all-trans retinoic acid. The protein arginine methyltransferase 5 (PRMT5) is involved in tumorigenesis. However, little is known about the biological function and therapeutic potential of PRMT5 in APL. Here we show that PRMT5 is highly expressed in APL patients. PRMT5 promotes APL by interacting with PML-RAR $\alpha$ and suppressing its ubiquitination and degradation. Mechanistically, PRMT5 attenuates the interaction between PML-RAR $\alpha$ and its ubiquitin E3 ligase RNF4 by methylating RNF4 at Arg164. Notably, $\mathrm{As}_{2} \mathrm{O}_{3}$ treatment triggers the dissociation of PRMT5 from PML nuclear bodies, attenuating RNF4 methylation and promoting RNF4-mediated PML-RAR $\alpha$ ubiquitination and degradation. Moreover, knockdown of PRMT5 and pharmacological inhibition of PRMT5 with the specific inhibitor EPZ015666 significantly inhibit APL cells growth. Combination of EPZ015666 with $\mathrm{As}_{2} \mathrm{O}_{3}$ shows synergistic effects on $\mathrm{As}_{2} \mathrm{O}_{3}$-induced differentiation of bone marrow (BM) cells from APL mice, as well as on apoptosis and differentiation in primary APL cells from APL patients. These findings provide mechanistic insight into the function of PRMT5 in APL pathogenesis and demonstrate that inhibition of PRMT5 or in combination with $\mathrm{As}_{2} \mathrm{O}_{3}$ might be a promising therapeutic strategy against APL.
\end{abstract}

\title{
Keywords:
}

PRMT5, PML-RAR $\alpha$, RNF4, methylation, ubiquitination, acute promyelocytic leukemia 


\section{Introduction}

Acute promyelocytic leukemia (APL) is a hematological malignancy that is a subtype of acute myeloid leukemia (AML) [1]. APL is mainly driven by an oncoprotein encoded by a fusion gene consisting of the $\mathrm{N}$ terminus of promyelocytic leukemia protein (PML) and the $\mathrm{C}$ terminus of retinoic acid receptor $\alpha(\mathrm{RAR} \alpha)[2,3]$. PML-RAR $\alpha$ functions as a transcriptional repressor of related genes and attenuates the assembly and function of PML nuclear bodies (PML-NBs), which results in deregulation of transcription, differentiation arrest, and enhanced self-renewal of leukemia-initiating blast cells [4-6]. All-trans retinoic acid (ATRA) and arsenic trioxide $\left(\mathrm{As}_{2} \mathrm{O}_{3}\right)$ are currently used for the clinical treatment of APL $[7,8]$. The combination of ATRA with $\mathrm{As}_{2} \mathrm{O}_{3}$ or chemotherapy dramatically improves the prognosis of APL patients [9]. Mechanistically, these combination therapies have produced better APL patient outcomes by promoting PMLRAR $\alpha$ degradation and thus inducing the differentiation of APL blasts and decreasing the abundance of leukemia-initiating cells $[10,11]$. PML-RAR $\alpha$ degradation is a SUMO-triggered and RNF4/ubiquitination-mediated process [12, 13]. However, this therapeutic scheme may cause serious side events such as systemic infection and secondary leukemia $[14,15]$. In addition, some APL patients fail to respond to therapy targeting PML-RAR $\alpha$ or relapse after a complete remission [16-18].

Recent studies have reported that protein arginine methyltransferases (PRMTs) function in several cancers, in which they play a role in methylation of protein arginine residues $[19,20]$. PRMTs are a group of proteins with 11 known members that can catalyze the addition of one or two methyl groups to the guanidine nitrogen atoms of an arginine residue $[21,22]$. Among the members of the PRMT family, PRMT5 has been a focus of significant attention in cancer research [23-25]. Overexpression of PRMT5 has been reported in hematologic malignancies, and PRMT5 has been shown 
to regulate proliferation and self-renewal of chronic myeloid leukemia (CML) stem cells [26]. However, the role of PRMT5 in APL has not been defined.

In this study, we investigated the expression and roles of PRMT5 in APL cell lines and primary APL cells from patients. We found that PRMT5 promotes the growth of APL cells by inhibiting PML-RAR $\alpha$ ubiquitination. By methylating RNF4 at R164, PRMT5 inhibits the interaction between PML-RAR $\alpha$ and RNF4. Inhibition of PRMT5 activity in combination with $\mathrm{As}_{2} \mathrm{O}_{3}$ promotes differentiation of BM cells from APL mice and primary APL cells from APL patients. These results demonstrate the oncogenic role of PRMT5 in APL pathogenesis, and provide a rationale for a therapeutic strategy targeting PRMT5 in APL treatment. 


\section{Materials and Methods}

\section{Animal Studies}

APL mice models were induced by intravenously injecting NOD-SCID mice with NB4 cells [27]. All mice were housed in specific pathogen-free barrier facilities. BM cells were isolated from mice and analyzed by CD11b-staining to determine differentiation rate. Animals were handled following the 'Principles for the Utilization and Care of Vertebrate Animals' and the 'Guide for the Care and Use of Laboratory Animals'. Animal studies were approved by the IACUC of the Center for Experimental Animal Research (China) and Peking University Laboratory Animal Center (IACUC No. LSCZhengX-2-1).

\section{Primary human leukemia samples}

Primary APL and normal mononuclear cells were freshly obtained from the bone marrow (BM) tissue of APL patients and healthy donors at the Institute of Hematology and Blood Diseases Hospital of Peking Union Medical College (PUMC). Informed consent was obtained from all participants in accordance with the Declaration of Helsinki. The study was approved by the Ethics Committee of Peking University (IRB00001052-16020).

\section{His-ubiquitin pulldown assay}

His-ubiquitin pulldown assays were performed following a method described in a previous study [28]. Briefly, HEK293T cells were transfected with his-ubiquitin and the indicated plasmids. After $48 \mathrm{~h}$, the cells were harvested and lysed in His-pulldown buffer. The lysate was incubated with $60 \mu \mathrm{L}$ of $\mathrm{Ni}^{2+}$ beads for $4 \mathrm{~h}$ and then washed 4 times with wash buffer. The beads were denatured with $2 \times$ SDS loading buffer and ubiquitin was assessed using the indicated antibodies. 


\section{Clonogenic survival assay}

First, 150-750 cells were seeded in solid agarose medium in 6-well plates in triplicate. After $24 \mathrm{~h}$, cells were cultured in medium containing a different concentration of EPZ015666. After 12 days, the number of clones was counted. The survival fraction was normalized to the number of untreated cells.

\section{Duolink proximity ligation assay (PLA)}

To detect the interaction between PRMT5 and PML-RAR $\alpha /$ RNF4, we used the Duolink $^{\circledR}$ In Situ PLA ${ }^{\circledR}$ kit (DUO92101, Sigma-Aldrich). Duolink proximity ligation assay was performed following the method of manufacture [29]. Fluorescence images were obtained under a confocal laser scanning microscope (Zeiss LSM 710) using a $63 \times$ oil objective lens.

\section{His-ubiquitin immunoprecipitation assay}

HEK293T cells were transfected with his-ubiquitin and the other indicated plasmids. After $48 \mathrm{~h}$, the cells were harvested, lysed in RIPA buffer and sonicated. The supernatants were incubated with the indicated antibodies at $4^{\circ} \mathrm{C}$ for $4 \mathrm{~h}$ or overnight, followed by incubation with $30 \mu \mathrm{L}$ protein $\mathrm{G}$ beads for $3 \mathrm{~h}$. Finally, the beads were washed 3 times using RIPA buffer and denatured with $2 \times$ SDS loading buffer. Ubiquitin was assessed using anti-his or anti-ubiquitin antibodies.

\section{In vitro methylation assay}

Recombinant GST-fusion protein RNF4 WT and RNF4 R164K were expressed in E. coli BL21 and purified using a glutathione-Sepharose 4B column (GE Healthcare). Myc-tagged PRMT5 was immunoprecipitated from transfected HEK293T cells. GSTRNF4 WT/R164K fusion protein and immunoprecipitated PRMT5 protein were incubated in $30 \mu \mathrm{L}$ of $5 \mathrm{mM} \mathrm{MgCl}_{2}, 20 \mathrm{mM}$ HEPES, $1 \mathrm{mM}$ ethylenediaminetetraacetic 
acid, 1 mM DTT, 10\% glycerol, $100 \mu \mathrm{M}$ S-(5'-Adenosyl)-L-methionine iodide (Sigma Aldrich) and $\mathrm{pH} 7.9$ at $37^{\circ} \mathrm{C}$ for $1 \mathrm{~h}$. The reaction stopped with SDS sample buffer was subjected to SDS-PAGE and immunoblot with SDMe and RNF4 antibodies.

\section{In vitro ubiquitination assay}

HEK293T cells were co-transfected with Flag-PML-RAR $\alpha$ and His-SUMO2. After 48 hours, cells were harvested and precipitated using Flag beads. Flag-PML-RAR $\alpha$ was eluted using Flag peptide. SUMOylated Flag-PML-RAR $\alpha$ was precipitated using $\mathrm{Ni}^{2+}$ beads. His-SUMO2-Flag-PML-RAR $\alpha$, GST-RNF4 WT/R164K, $10 \mu \mathrm{M}$ UBE1 (R\&D Systems), $1 \mu \mathrm{M}$ UbcH5a (R\&D Systems) and $1 \mathrm{mM}$ ubiquitin were incubated together in reaction buffer (50 mM Tris- $\mathrm{HCl}, 5 \mathrm{mM} \mathrm{MgCl}, 2 \mathrm{mM}$ ATP, 1 mM DTT, pH 7.5) at $37^{\circ} \mathrm{C}$ for $4 \mathrm{~h}$. RNF4 ubiquitination was detected by western blotting with anti-ubiquitin antibodies.

\section{Statistical analysis}

Statistical analysis was performed using Student's $t$-test. All of the results are presented as mean $\pm \operatorname{SEM}(* P<0.05, * * P<0.01, * * * P<0.001, * * * * P<0.0001)$.

Additional information of materials and methods are described in the Supplementary Information. 


\section{Results}

\section{PRMT5 is highly expressed in APL cells and interacts with PML-RAR $\alpha$}

Previous studies have shown that the oncogenic fusion protein PML-RAR $\alpha$ plays an important role in the process of APL development [30, 31]. The arginine methyltransferase PRMT5 has attracted significant attention for its clinical effect on tumorigenesis and its exceptional levels of accumulation in colon, breast and blood cancers [32]. To examine whether PRMT5 is involved in the pathogenesis of APL, we analyzed the protein levels of PRMT5 in APL patient samples. We found that the abundance of PRMT5 in BM from APL patients was significantly higher than that of normal cells (Fig. 1A), and PRMT5 expression was positively correlated with the level of PML-RAR $\alpha$ (Fig. 1A). Futhermore, BM from APL patients expressed higher mRNA levels of PML-RAR $\alpha$ and PRMT5 than that of healthy donors (Fig. 1B and 1C). To illustrate the regulatory mechanism of PRMT5 in APL, we determined whether PRMT5 could interact with PML-RAR $\alpha$. Co-immunoprecipitation (co-IP) assays showed that Flag-tagged PML-RAR $\alpha$ was associated with endogenous PRMT5 (Supplementary Fig. S1A). Moreover, the endogenous interaction between PRMT5 and PML-RAR $\alpha$ was confirmed in human leukemia NB4 cells, an APL cell line in which PML-RAR $\alpha$ is expressed endogenously (Fig. 1D). The immunofluorescence experiments also showed that endogenous PML-RAR $\alpha$ and PRMT5 co-localized in NB4 cells (Fig. 1E), and this observation was verified by a PLA, which allowed us to detect in situ protein interaction with high specificity and sensitivity (Fig. 1F). Taken together, these findings demonstrate that PRMT5 is elevated in APL and is a novel partner of PML-RAR $\alpha$.

\section{PRMT5 promotes the stability of PML-RAR $\alpha$}

Targeting PML-RAR $\alpha$ for degradation is a conventional strategy for APL treatment [27, 33]. Because PRMT5 is associated with PML-RAR $\alpha$, we next explored the effect of 
PRMT5 on the expression level of PML-RAR $\alpha$. We found that knockdown of PRMT5 in HEK293T cells decreased the protein abundance of PML-RAR $\alpha$ (Supplementary Fig. S1B). Moreover, we assessed the effect of PRMT5 on the protein stability of endogenous PML-RAR $\alpha$ in NB4 cells. As expected, knockdown of PRMT5 decreased the abundance of PML-RAR $\alpha$ in NB4 cells (Fig. 2A). However, overexpression of PRMT5 had no influence on the mRNA abundance of PML-RAR $\alpha$ (Fig. 2B), suggesting that PRMT5 regulates PML-RAR $\alpha$ at the protein level rather than promoting its transcription.

Because PRMT5 is a methyltransferase, we tested whether the methyltransferase activity of PRMT5 plays a role in its effect on the stability of PML-RAR $\alpha$. We thus constructed an enzymatically inactive mutant form of PRMT5, PRMT5 G367A/R368A, in which the enzymatic sites Gly367 and Arg368 were mutated to Ala. Different from the wild-type PRMT5 that promoted PML-RAR $\alpha$ stability, PRMT5 G367A/R368A mutant did not affect the stability of PML-RAR $\alpha$ (Fig. 2C), suggesting that the methyltransferase activity of PRMT5 is critical for its effect on PML-RAR $\alpha$. Collectively, these results indicate that PRMT5 enhances the stability of PML-RAR $\alpha$.

\section{PRMT5 inhibits ubiquitination of PML-RARa by interacting with RNF4}

Previous studies revealed that degradation of PML-RAR $\alpha$ induced by $\mathrm{As}_{2} \mathrm{O}_{3}$ treatment is achieved through a SUMO-dependent, ubiquitin-mediated process [12, 13]. SUMOylation of PML-RAR $\alpha$ triggers RNF4-mediated ubiquitination and degradation; therefore, the stability of PML-RAR $\alpha$ is regulated by SUMOylation and ubiquitination. We examined whether PRMT5 affected the stability of PML-RAR $\alpha$ by modulating its SUMOylation and ubiquitination in cells treated with or without $\mathrm{As}_{2} \mathrm{O}_{3}$. The results of His-pull down assays showed that PRMT5 inhibited ubiquitination of PML-RAR $\alpha$ (Supplementary Fig. S2A), but it had no effect on its SUMOylation (Supplementary 
Fig. S2B). Moreover, the inhibitory effect of PRMT5 on the PML-RAR $\alpha$ ubiquitination was confirmed by immunoprecipitation assays under denatured condition (Fig. 2D). In contrast, knockdown of PRMT5 significantly increased PML-RAR $\alpha$ ubiquitination (Fig. 2E). Consistently, Duolink PLA assays revealed that knockdown of PRMT5 promoted ubiquitination of PML-RAR $\alpha$ in NB4 cells (Fig. 2F). Next, using His-pull down assays, we showed that PRMT5 inhibited K48-linked ubiquitination, but it had no effect on K63-linked ubiquitination of PML-RAR $\alpha$ (Supplementary Fig. S2C).

To clarify how PRMT5 regulates RNF4-mediated PML-RAR $\alpha$ ubiquitination, we investigated whether PRMT5 functions by affecting the interaction between RNF4 and its substrate PML-RAR $\alpha$. The results of co-IP experiments showed that overexpression of PRMT5 attenuated the PML-RAR $\alpha-R N F 4$ interaction (Fig. 3A). Moreover, because RNF4 is a poly-SUMO-specific ubiquitin E3 ligase, which binds to the poly-SUMO chain of PML-RAR $\alpha$ to induce PML-RAR $\alpha$ degradation [12], we assessed whether PRMT5 inhibited the interaction between RNF4 and SUMO-modified PML-RAR $\alpha$ by performing an in vitro interaction assay (Fig. 3B). As expected, PRMT5 inhibited the interaction between RNF4 and SUMOylated PML-RAR $\alpha$ (Fig. 3C). Based on these findings, we hypothesized that PRMT5 is likely interacted with RNF4. Indeed, the results of co-IP and PLA assays showed that PRMT5 interacted with both exogenous and endogenous RNF4 (Fig. 3D and 3E; Supplementary Fig. S2D). Furthermore, identification of the critical domain responsible for the binding of PRMT5 to RNF4 revealed that the RING finger domain of RNF4 and the $\beta$-Barrel domain of PRMT5 were necessary for PRMT5-RNF4 binding (Fig. 3F and 3G). Collectively, our findings demonstrate that PRMT5 represses PML-RAR $\alpha$ ubiquitination by blocking the interaction between RNF4 and SUMOylated PML-RAR $\alpha$.

\section{RNF4 is methylated at R164 by PRMT5}


PRMT5 is a type II arginine methyltransferase that adds two symmetric methyl groups to the arginine residue of its substrates [34]. Since PRMT5 is associated with RNF4, we speculated that RNF4 is a substrate of PRMT5. To test this hypothesis, we first examined whether RNF4 is methylated with an antibody against symmetric dimethylated arginine. Indeed, RNF4 showed a methylation signal at the expected position (Fig. 4A). Next, using mass spectrometry, we identified arginine 164 as the methylation site of RNF4 (Fig. 4B). Mutation of Arg164 to Lys obviously reduced the level of PRMT5/MEP50-mediated RNF4 methylation (Fig. 4C), and RNF4 Arg164 is highly conserved in various vertebrate species (Fig. 4D). Moreover, in vitro methylation assay also supported that PRMT5 catalyzed RNF4 methylation (Fig. 4E). As Arg164 is located in the RING finger domain of RNF4, to further investigate the effect of RNF4 R164 methylation on its regulatory function, we examined whether RNF4 R164 methylation affects PML-RAR $\alpha$ ubiquitination by in vitro ubiquitination assays using SUMOylated PML-RAR $\alpha$ proteins (prepared as shown in Fig. 4F). The WT RNF4 and R164K mutant were capable of ubiquitinating PML-RAR $\alpha$ (Fig. 4G), suggesting that RNF4 methylation did not attenuate its ubiquitin E3 ligase activity. These results demonstrate that the R164 site of RNF4 is methylated by PRMT5, and this methylation has no effect on its E3 enzyme activity.

\section{RNF4 methylation inhibits PML-RAR $\alpha$ ubiquitination and degradation by blocking the RNF4-PML-RAR $\alpha$ interaction}

The results described above suggest that RNF4 is a substrate for PRMT5, but methylation of RNF R164 does not affect its ubiquitin E3 ligase activity. To explore whether methylation of RNF4 influences binding between RNF4 and PML-RAR $\alpha$, we detected the association of PML-RAR $\alpha$ with WT RNF4 or the RNF R164K mutant in cells treated with $\mathrm{As}_{2} \mathrm{O}_{3}$. In comparison with WT RNF4, the RNF4 R164K mutant 
showed a stronger interaction with PML-RAR $\alpha$ in the presence of $\mathrm{As}_{2} \mathrm{O}_{3}$ (Fig. 5A). Also, PRMT5-catalyzed methylation of RNF4 inhibited the RNF4-PML-RAR $\alpha$ interaction (Fig. 5B). In addition, Co-IP assays showed that treatment with $\mathrm{As}_{2} \mathrm{O}_{3}$ disturbed the interaction of PRMT5 with PML-RAR $($ Fig. 5C) or RNF4 (Supplementary Fig. S3A), while promoting the RNF4-PML-RAR $\alpha$ interaction (Fig. 5C and Supplementary Fig. S3B). Consistently, we found that the abundance of WT RNF4 methylated by PRMT5 gradually decreased following $\mathrm{As}_{2} \mathrm{O}_{3}$ treatment (Fig. 5D). It has been reported that $\mathrm{As}_{2} \mathrm{O}_{3}$ triggers the recruitment of RNF4 to PML nuclear bodies and promotes PML or PML-RAR $\alpha$ ubiquitination and proteasome-dependent degradation [13]. Therefore, we determined whether $\mathrm{As}_{2} \mathrm{O}_{3}$ could inhibit the interaction between PRMT5 and RNF4 by affecting the localization of PRMT5 within PML nuclear bodies. As we predicted, IF assays showed that the localization of PRMT5 in PML nuclear bodies was reduced significantly at 30 min after $\mathrm{As}_{2} \mathrm{O}_{3}$ treatment (Fig. 5E). These results indicate that $\mathrm{As}_{2} \mathrm{O}_{3}$ treatment results in the dissociation of PRMT5 from PML nuclear bodies, and thus PRMT5 no longer interacts with and methylates RNF4. Given our findings that PRMT5 modulates PML-RAR $\alpha$ turnover (Fig. 2) and the RNF4 R164K mutant has a stronger interaction with PML-RAR $\alpha$ (Fig. 5A), we determined whether PRMT5 suppresses PML-RAR $\alpha$ ubiquitination and promotes PML-RAR $\alpha$ abundance by regulating RNF4 methylation. We separately measured the effects of RNF4 WT and the R164K mutant on PML-RAR $\alpha$ ubiquitination, as well as the half-life of the PML-RAR $\alpha$ protein. As shown in Fig. 5F, the RNF4 R164K mutant led to increased PML-RAR $\alpha$ ubiquitination in the absence and presence of $\mathrm{As}_{2} \mathrm{O}_{3}$. In addition, the RNF4 R164K mutant promoted PML-RAR $\alpha$ degradation (Fig. 5G left panel and Fig. 5H) and accelerated $\mathrm{As}_{2} \mathrm{O}_{3}$-induced PML-RAR $\alpha$ degradation (Fig. 5G right panel and Fig. 5H). Taken together, our results indicate that PRMT5 stabilizes 
PML-RAR $\alpha$ by catalyzing RNF4 methylation which inhibits the interaction between RNF4 and PML-RAR $\alpha$.

\section{Inhibition of PRMT5 enhances the therapeutic efficacy of $\mathrm{As}_{2} \mathrm{O}_{3}$ in APL}

The results described above suggest that PRMT5 might regulate the progression of APL by modulating PML-RARa stability. We constructed NB4 cell lines that stably expressed PRMT5 or PRMT5 shRNA. The cell viability assays revealed that PRMT5 overexpression enhanced NB4 cell viability, while PRMT5 knockdown inhibited NB4 cell viability (Fig. 6A). We also examined the influence of PRMT5 on NB4 cell proliferation using colony formation assays. The number of NB4 clones was reduced by depletion of PRMT5, but it was increased by PRMT5 overexpression (Fig. 6B). As PRMT5 stabilized PML-RAR $\alpha$ by methylating RNF4, we assumed that combination of the PRMT5 inhibitor EPZ015666 with $\mathrm{As}_{2} \mathrm{O}_{3}$ might have synergistic effects. As expected, in comparison to the effect of $\mathrm{As}_{2} \mathrm{O}_{3}$ or EPZ015666 alone, the combination of $\mathrm{As}_{2} \mathrm{O}_{3}$ with EPZ015666 more efficiently destabilized PML-RAR $\alpha$ in NB4 cells (Fig. 6C). Consistently, we found that EPZ015666 inhibited the growth of NB4 cells, and the combination of EPZ015666 with $\mathrm{As}_{2} \mathrm{O}_{3}$ further suppressed the growth of APL cells (Fig. 6D and 6E). Moreover, EPZ015666 potently increased the apoptosis and differentiation percentages of NB4 cells induced by $\mathrm{As}_{2} \mathrm{O}_{3}$ treatment (Fig. 6F). Taken together, these data suggest that the combination of PRMT5 inhibitor EPZ015666 with $\mathrm{As}_{2} \mathrm{O}_{3}$ enhances the therapeutic efficacy of $\mathrm{As}_{2} \mathrm{O}_{3}$ in NB4 cells.

Next, we explored the biological significance of PRMT5 inhibition by using APL mice models. BM cells were isolated from APL mice and treated with $\mathrm{As}_{2} \mathrm{O}_{3}$ or/and EPZ015666 and then the differentiation rate was examined (Fig. 7A). Consistent with the observations in NB4 cells, the combination of EPZ015666 with $\mathrm{As}_{2} \mathrm{O}_{3}$ showed synergistic effects on differentiation in BM cells from APL mice (Fig. 7B), which was 
further confirmed in primary APL cells derived from patients (Fig. 7C and 7D). Together, these results suggest that PRMT5 plays a critical role in APL pathogenesis, and the combination of PRMT5 inhibitor EPZ015666 with $\mathrm{As}_{2} \mathrm{O}_{3}$ significantly enhances anti-APL efficacy.

Because drug resistance due to PML-RAR $\alpha$ mutations is an intractable problem in APL therapy, we further investigated the effects of PRMT5 inhibitor EPZ015666 on clinically reported $\mathrm{As}_{2} \mathrm{O}_{3}$-resistant mutants including $\mathrm{C} 212 \mathrm{~A}, \mathrm{C} 213 \mathrm{~A}, \mathrm{~A} 216 \mathrm{~V}$, or S220G [35]. EPZ015666 treatment reduced the abundance of PML-RAR $\alpha$ in cells harboring $\mathrm{As}_{2} \mathrm{O}_{3}$-resistant PML-RAR $\alpha$ mutations (Fig. 7E). Besides, we found that the proteasome inhibitor MG132 reduced the EPZ015666-induced PML-RAR $\alpha$ degradation of $\mathrm{As}_{2} \mathrm{O}_{3}$-resistant mutants, C212A and S220G, suggesting that EPZ015666 promotes PML-RAR $\alpha$ degradation by proteasome degradation pathway (Fig. 7F). These data indicates that inhibition of PRMT5 can promote the degradation of the PML-RAR $\alpha$ protein, which could be potentially used to treat $\mathrm{As}_{2} \mathrm{O}_{3}$-resistant APL patients. 


\section{Discussion}

In this study, we demonstrated the regulatory role of arginine methyltransferase PRMT5 in PML-RAR $\alpha$ degradation and APL development. We found that PRMT5 promotes PML-RAR $\alpha$ stability by methylating RNF4 at R164, which blocks the interaction of RNF4 with PML-RAR $\alpha$ and subsequently inhibits ubiquitination of PML-RAR $\alpha$ and enhances the stability of PML-RAR $\alpha$, thus inhibiting apoptosis and differentiation of APL cells. Following $\mathrm{As}_{2} \mathrm{O}_{3}$ treatment, PRMT5 dissociates from PML nuclear bodies, while RNF4 shuttles into PML nuclear bodies, which promotes the interaction of RNF4 with PML-RAR $\alpha$ and accelerates PML-RAR $\alpha$ degradation. Furthermore, inhibition of PRMT5 by administration of its inhibitor EPZ015666 eradicates APL cells and enhances the sensitivity of APL cells to $\mathrm{As}_{2} \mathrm{O}_{3}$ by accelerating PML-RAR $\alpha$ degradation (Fig. 8).

Previous studies demonstrated that PML-RAR $\alpha$ degradation is mediated by SUMOylation and ubiquitination $[12,13] . \mathrm{As}_{2} \mathrm{O}_{3}$-induced PML-RAR $\alpha$ SUMOylation triggered RNF4-mediated ubiquitination, degradation and differentiation of PMLRAR $\alpha$ [36]. SUMOylation is critically important for enhanced PML/PML-RAR $\alpha$ degradation during the early drug treatment stage. The S214L mutation of PML-RAR $\alpha$ can disrupt the organization of PML nuclear bodies and changes in dynamics, producing resistance to both $\mathrm{As}_{2} \mathrm{O}_{3}$ and ATRA [37, 38]. PCGF2, a Polycomb group protein, can form the PCGF2-UBE2I complex with UBE2I to impede PML-RAR $\alpha$ degradation. However, $\mathrm{As}_{2} \mathrm{O}_{3}$ facilitates disruption of the PCGF2-UBE2I complex, and UBE2I interacts with PML-RAR $\alpha$, which induces PML-RAR $\alpha$ SUMOylation and subsequent degradation [39]. Interestingly, here we found that PRMT5 inhibited ubiquitination, rather than SUMOylation, of PML-RAR $\alpha$ (Fig. 2D and 2E; Supplementary S3A and S3B), indicating that PRMT5 regulates PML-RAR $\alpha$ abundance by influencing the 
ubiquitination process. Notably, PRMT5 methyltransferase activity is essential in its regulation of PML-RAR $\alpha$ stability. PRMT5 and PRMT9 are type II PRMTs that catalyze mono- and symmetric di-methylation and function similarly in several biological processes [40]. We explored whether PRMT9 affected the stability of PMLRAR $\alpha$ as PRMT5 did. No influence of PRMT9 on PML-RAR $\alpha$ stability was observed in cells transfected with different amounts of PRMT9 (Supplementary Fig. S4A and S4B), suggesting that the stability of PML-RAR $\alpha$ is affected by PRMT5 specifically. We also found that PRMT5 interacted with and methylated RNF4 at R164 in its RING finger domain, which is necessary for PRMT5 binding (Fig. 3D-G and Fig. 4A-C). Furthermore, PRMT5-catalyzed methylation of RNF4 blocked its interaction with PML-RAR $\alpha$, thus stabilizing PML-RAR $\alpha$ and promoting APL (Fig. 5B and 5F). In addition, we showed that PRMT5 did not methylate PML-RAR $\alpha$ (Supplementary Fig. S5). This is the first study showing that the abundance of PML-RAR $\alpha$ is regulated by methyltransferase PRMT5 through methylation of RNF4. Identification of the PRMT5RNF4-PML-RAR $\alpha$ axis by this study revealed a novel mechanism underlying APL pathogenesis. However, further studies are necessary to investigate whether methylation of RNF4 causes conformational changes and subsequently inhibits PMLRAR $\alpha$ binding.

A previous study demonstrated that $\mathrm{As}_{2} \mathrm{O}_{3}$ treatment induces considerable aggregation of RNF4 in PML nuclear bodies [13]. In this study, we found that $\mathrm{As}_{2} \mathrm{O}_{3}$ treatment attenuated the interaction between PRMT5 and RNF4 and increased the association between RNF4 and PML-RAR $\alpha$, while inhibiting RNF4 methylation, due to the dissociation of PRMT5 from PML nuclear bodies induced by $\mathrm{As}_{2} \mathrm{O}_{3}$. Accordingly, the RNF4 R164K mutant strongly interacted with PML-RAR $\alpha$, which promoted ubiquitination of PML-RAR $\alpha$ and expedited its degradation (Fig. 5). 
PRMT5 has been reported to function in several hematological malignancies, such as acute lymphoblastic leukemia (ALL) [41], acute myeloid leukemia (AML) [42, 43], chronic myelogenous leukemia (CML) and multiple myeloma (MM) [26]. PRMT5 regulates the binding of the splicing regulator SRSF1 to mRNAs and proteins by methylating SRSF1, which promotes the survival of AML cells and provides potential biomarkers for the treatment response to PRMT5 inhibitors [43]. PRMT5-mediated H4R3sme2 inhibits cell differentiation in pediatric ALL [41]. The regulatory mechanisms underlying these effects of PRMT5 on hematological malignancies are mainly by regulating transcription, either through catalyzing symmetric dimethylation of histone protein to regulate gene transcription or by methylating transcription factors to alter their transcriptional activities [44]. In this study, we demonstrated that PRMT5 promotes APL progression by regulating the protein level of oncogene PML-RAR $\alpha$. Ours and previous studies indicate that PRMT5 regulates blood cancers through distinct mechanisms.

Our study demonstrates the critical role of PRMT5 in APL pathogenesis and suggests that inhibition of PRMT5 might be a potential therapeutic option against APL. Indeed, we found that EPZ015666, a recently identified selective and orally bioavailable PRMT5 inhibitor [45], inhibited APL cell proliferation and increased APL cell differentiation. Notably, the combination of EPZ015666 with $\mathrm{As}_{2} \mathrm{O}_{3}$ enhanced the therapeutic efficacy of $\mathrm{As}_{2} \mathrm{O}_{3}$ in $\mathrm{BM}$ from APL mice (Fig. 7A and 7B), as well as in primary APL cells from APL patients (Fig. 7C and 7D).

Maimaitiyiming et al. recently reported that hyperthermia destabilized PML/RAR $\alpha$ protein in clinically identified $\mathrm{As}_{2} \mathrm{O}_{3}$-resistant mutants via the SIAH2 E3 ligase, which is distinct from that of arsenic therapy. And hyperthermia and $\mathrm{As}_{2} \mathrm{O}_{3}$ treatment act 
synergistically in destabilizing PML-RAR $\alpha$ [35]. Here we found that EPZ015666 could induce degradation of $\mathrm{As}_{2} \mathrm{O}_{3}$-resistant PML-RAR $\alpha$ mutants by the proteasome degradation pathway (Fig. 7E and 7F). Although the clinical therapeutic efficacy for refractory or relapsed APL patients by using the combination of EPZ015666 with $\mathrm{As}_{2} \mathrm{O}_{3}$ remains to be explored, our study suggests that EPZ015666 could overcome $\mathrm{As}_{2} \mathrm{O}_{3}$ resistance and is a promising candidate agent for APL.

In conclusion, our study reveals the critical role of the PRMT5/RNF4/PML-RAR $\alpha$ axis in APL cells and establishes a rational approach for the combination of $\mathrm{As}_{2} \mathrm{O}_{3}$ with PRMT5 inhibitor for the treatment of patients with APL.

\section{Availability of data and materials}

The data and materials are available by contacting the corresponding author upon reasonable request.

\section{Acknowledgements}

This work was supported by the National Natural Science Foundation of China (grant nos. 82130081 and 81730080), Natural Science Foundation of Beijing Municipality (5212008). We thank the National Center for Protein Sciences and the Core Facilities of Life Sciences at Peking University, particularly Guilan Li, Dong Liu, Yinghua Guo, Liying Du, Hongxia Lv, Siying Qin, and Xiaochen Li for technical help.

\section{Author Contributions:}

Y. Yang, X. Huang and X. Zheng designed this study. Y. Yang, X. Huang, D. Zhu performed the experiments. X. Huang and Y. Yang analyzed the data and wrote the manuscript. K Li and $\mathrm{H}-\mathrm{H}$ Zhu provided NOD-SCID mice and APL patient samples. X. 
Zheng supervised this study and wrote the manuscript.

\section{Ethics declarations}

\section{Competing Interest:}

The authors declare no potential conflicts of interest.

\section{Ethics approval}

Animal studies were performed with ethics approval authorized by the IACUC of the Center for Experimental Animal Research (China) and Peking University Laboratory Animal Center (IACUC No. LSCZhengX-2-1). The study of APL patients was approved by the Ethics Committee of Peking University (IRB00001052-16020) and in accordance with the principles of the Declaration of Helsinki. 


\section{References}

1. de The H, Chen Z. Acute promyelocytic leukaemia: novel insights into the mechanisms of cure. Nat Rev Cancer. 2010;10(11):775-83.

2. Burnett AK, Russell NH, Hills RK, Bowen D, Kell J, Knapper S, et al. Arsenic trioxide and all-trans retinoic acid treatment for acute promyelocytic leukaemia in all risk groups (AML17): results of a randomised, controlled, phase 3 trial. Lancet Oncol. 2015;16(13):1295-305.

3. Strocchio L, Gurnari C, Santoro N, Putti MC, Micalizzi C, Zecca M, et al. Arsenic trioxide and all-trans retinoic acid treatment for childhood acute promyelocytic leukaemia. Br J Haematol. 2019;185(2):360-3.

4. Lallemand-Breitenbach V, de The H. PML nuclear bodies. Cold Spring Harb Perspect Biol. 2010;2(5):a000661.

5. Kwok C, Zeisig BB, Dong S, So CW. Forced homo-oligomerization of RARalpha leads to transformation of primary hematopoietic cells. Cancer Cell. 2006;9(2):95108.

6. Martens JH, Brinkman AB, Simmer F, Francoijs KJ, Nebbioso A, Ferrara F, et al. PML-RARalpha/RXR Alters the Epigenetic Landscape in Acute Promyelocytic Leukemia. Cancer Cell. 2010;17(2):173-85.

7. Kayser S, Schlenk RF, Platzbecker U. Management of patients with acute promyelocytic leukemia. Leukemia. 2018;32(6):1277-94.

8. Coombs CC, Tavakkoli M, Tallman MS. Acute promyelocytic leukemia: where did we start, where are we now, and the future. Blood Cancer J. 2015;5:e304.

9. Lo-Coco F, Avvisati G, Vignetti M, Thiede C, Orlando SM, Iacobelli S, et al. Retinoic acid and arsenic trioxide for acute promyelocytic leukemia. N Engl J Med. 2013;369(2):111-21.

10. Lallemand-Breitenbach V, Zhu J, Chen Z, de The H. Curing APL through PML/RARA degradation by As2O3. Trends Mol Med. 2012;18(1):36-42.

11. Dos Santos GA, Kats L, Pandolfi PP. Synergy against PML-RARa: targeting transcription, proteolysis, differentiation, and self-renewal in acute promyelocytic leukemia. J Exp Med. 2013;210(13):2793-802.

12. Tatham MH, Geoffroy MC, Shen L, Plechanovova A, Hattersley N, Jaffray EG, et al. RNF4 is a poly-SUMO-specific E3 ubiquitin ligase required for arsenic-induced PML degradation. Nat Cell Biol. 2008;10(5):538-46.

13. Lallemand-Breitenbach V, Jeanne M, Benhenda S, Nasr R, Lei M, Peres L, et al. Arsenic degrades PML or PML-RARalpha through a SUMO-triggered RNF4/ubiquitin-mediated pathway. Nat Cell Biol. 2008;10(5):547-55.

14. Lu Y, Yan JS, Xia L, Qin K, Yin QQ, Xu HT, et al. 2-Bromopalmitate targets retinoic acid receptor alpha and overcomes all-trans retinoic acid resistance of acute promyelocytic leukemia. Haematologica. 2019;104(1):102-12.

15. Gaut D, Sasine J, Schiller G. Secondary clonal hematologic neoplasia following successful therapy for acute promyelocytic leukemia (APL): A report of two cases and review of the literature. Leuk Res Rep. 2018;9:65-71.

16. Lehmann-Che J, Bally C, de The H. Resistance to therapy in acute promyelocytic leukemia. N Engl J Med. 2014;371(12):1170-2. 
17. Zhang X, Pan J. Resistance to arsenic trioxide and retinoic acid therapy in acute promyelocytic leukemia. Ann Hematol. 2017;96(4):707-8.

18. Zhu HH, Qin YZ, Huang XJ. Resistance to arsenic therapy in acute promyelocytic leukemia. N Engl J Med. 2014;370(19):1864-6.

19. Smith E, Zhou W, Shindiapina P, Sif S, Li C, Baiocchi RA. Recent advances in targeting protein arginine methyltransferase enzymes in cancer therapy. Expert Opin Ther Targets. 2018;22(6):527-45.

20.Jarrold J, Davies CC. PRMTs and Arginine Methylation: Cancer's Best-Kept Secret? Trends Mol Med. 2019;25(11):993-1009.

21. Pal S, Sif S. Interplay between chromatin remodelers and protein arginine methyltransferases. J Cell Physiol. 2007;213(2):306-15.

22. Blanc RS, Richard S. Arginine Methylation: The Coming of Age. Mol Cell. 2017;65(1):8-24.

23. Yan F, Alinari L, Lustberg ME, Martin LK, Cordero-Nieves HM, BanasavadiSiddegowda Y, et al. Genetic validation of the protein arginine methyltransferase PRMT5 as a candidate therapeutic target in glioblastoma. Cancer Res. 2014;74(6):1752-65.

24. Hu D, Gur M, Zhou Z, Gamper A, Hung MC, Fujita N, et al. Interplay between arginine methylation and ubiquitylation regulates KLF4-mediated genome stability and carcinogenesis. Nat Commun. 2015;6:8419.

25. Kanda M, Shimizu D, Fujii T, Tanaka H, Shibata M, Iwata N, et al. Protein arginine methyltransferase 5 is associated with malignant phenotype and peritoneal metastasis in gastric cancer. Int J Oncol. 2016;49(3):1195-202.

26. Jin Y, Zhou J, Xu F, Jin B, Cui L, Wang Y, et al. Targeting methyltransferase PRMT5 eliminates leukemia stem cells in chronic myelogenous leukemia. J Clin Invest. 2016;126(10):3961-80.

27. Li K, Wang F, Cao WB, Lv XX, Hua F, Cui B, et al. TRIB3 Promotes APL Progression through Stabilization of the Oncoprotein PML-RARalpha and Inhibition of p53-Mediated Senescence. Cancer Cell. 2017;31(5):697-710 e7.

28. Li T, Guan J, Huang Z, Hu X, Zheng X. RNF168-mediated H2A neddylation antagonizes ubiquitylation of $\mathrm{H} 2 \mathrm{~A}$ and regulates DNA damage repair. J Cell Sci. 2014;127(Pt 10):2238-48.

29. Zhu D, Xu R, Huang X, Tang Z, Tian Y, Zhang J, et al. Deubiquitinating enzyme OTUB1 promotes cancer cell immunosuppression via preventing ER-associated degradation of immune checkpoint protein PD-L1. Cell Death Differ. 2020.

30. de The H, Pandolfi PP, Chen Z. Acute Promyelocytic Leukemia: A Paradigm for Oncoprotein-Targeted Cure. Cancer Cell. 2017;32(5):552-60.

31. Cicconi L, Fenaux P, Kantarjian H, Tallman M, Sanz MA, Lo-Coco F. Molecular remission as a therapeutic objective in acute promyelocytic leukemia. Leukemia. 2018;32(8):1671-8.

32. Yang Y, Bedford MT. Protein arginine methyltransferases and cancer. Nat Rev Cancer. 2013;13(1):37-50.

33. Nasr R, Lallemand-Breitenbach V, Zhu J, Guillemin MC, de The H. Therapyinduced PML/RARA proteolysis and acute promyelocytic leukemia cure. Clin 
Cancer Res. 2009;15(20):6321-6.

34. Karkhanis V, Hu YJ, Baiocchi RA, Imbalzano AN, Sif S. Versatility of PRMT5induced methylation in growth control and development. Trends Biochem Sci. 2011;36(12):633-41.

35. Maimaitiyiming Y, Wang QQ, Yang C, Ogra Y, Lou YJ, Smith CA, et al. Hyperthermia Selectively Destabilizes Oncogenic Fusion Proteins. Blood Cancer Discov. 2021;2(4):388-401.

36. Zhu J, Zhou J, Peres L, Riaucoux F, Honore N, Kogan S, et al. A sumoylation site in PML/RARA is essential for leukemic transformation. Cancer Cell. 2005;7(2):14353.

37. Zhao S, Shi P, Zhong Q, Shao S, Huang Y, Sun Y, et al. Identification of a point mutation PML(S214L)-RARalpha that alters PML body organization, dynamics and SUMOylation. Biochem Biophys Res Commun. 2019;511(3):518-23.

38. Bai DM, Zheng XF. PML-RARA mutations confer varying arsenic trioxide resistance. Protein Cell. 2017;8(4):296-301.

39. Jo S, Lee YL, Kim S, Lee H, Chung H. PCGF2 negatively regulates arsenic trioxide-induced PML-RARA protein degradation via UBE2I inhibition in NB4 cells. Biochim Biophys Acta. 2016;1863(7 Pt A):1499-509.

40. Li ASM, Li F, Eram MS, Bolotokova A, Dela Sena CC, Vedadi M. Chemical probes for protein arginine methyltransferases. Methods. 2020;175:30-43.

41. Mei M, Zhang R, Zhou ZW, Ying Z, Wang J, Zhang H, et al. PRMT5-mediated H4R3sme2 Confers Cell Differentiation in Pediatric B-cell Precursor Acute Lymphoblastic Leukemia. Clin Cancer Res. 2019;25(8):2633-43.

42. Tarighat SS, Santhanam R, Frankhouser D, Radomska HS, Lai H, Anghelina M, et al. The dual epigenetic role of PRMT5 in acute myeloid leukemia: gene activation and repression via histone arginine methylation. Leukemia. 2016;30(4):789-99.

43. Radzisheuskaya A, Shliaha PV, Grinev V, Lorenzini E, Kovalchuk S, Shlyueva D, et al. PRMT5 methylome profiling uncovers a direct link to splicing regulation in acute myeloid leukemia. Nat Struct Mol Biol. 2019;26(11):999-1012.

44. Zhu F, Rui L. PRMT5 in gene regulation and hematologic malignancies. Genes Dis. 2019;6(3):247-57.

45. Chan-Penebre E, Kuplast KG, Majer CR, Boriack-Sjodin PA, Wigle TJ, Johnston LD, et al. A selective inhibitor of PRMT5 with in vivo and in vitro potency in MCL models. Nat Chem Biol. 2015;11(6):432-7. 


\section{Figure Legends}

Figure 1. PRMT5 is highly expressed in APL cells and interacts with PML-RAR $\alpha$. (A) Immunoblotting of PML-RAR $\alpha$ and PRMT5 expression in BM from healthy people (\#1 - \#6) and APL patients (\#1- \#5). (B-C) The qRT-PCR analyses of PML-RAR $\alpha$ (B) and PRMT5 (C) mRNA expression in BM from healthy donors and APL patients. (D) The endogenous interaction between PML-RAR $\alpha$ and PRMT5 was confirmed by co-IP experiments in NB4 cells. (E) Representative images of NB4 cells immunostaining for PRMT5 (red), PML-RAR $\alpha$ (green), and DAPI (blue). Scale bar, $10 \mu \mathrm{m}$. (F) Duolink PLA assays were performed to confirm the in situ interaction between PRMT5 and PML-RAR $\alpha$ (red dots) in NB4 cells. Scale bar, $10 \mu \mathrm{m}$. Quantification results for the PLA dots indicating PRMT5-PML-RAR $\alpha$ interaction are shown as mean $\pm \mathrm{SEM}$.

Figure 2. PRMT5 increases the stability of PML-RARa by reducing its ubiquitination. (A) The effect of depleted PRMT5 on PML-RAR $\alpha$ stability was analyzed by immunoblotting in PRMT5 knockdown and control NB4 cells. (B) The qRT-PCR analyses of PML-RAR $\alpha$ mRNA expression in HEK293T cell transfected with Myc-PRMT5 and Flag-PML-RAR $\alpha$. Statistical analysis was performed using Student's $t$-test. Data are shown as mean \pm SEM ( $n=3)$. NS, not significant. (C) The effect of PRMT5 enzymatic activity on PML-RAR $\alpha$ expression was analyzed by immunoblotting in HEK293T cells transfected with Flag-PML-RAR $\alpha$ and increasing amounts of PRMT5 wild-type or the enzymatically inactive PRMT5 G367A/R368A mutant (Left). Quantification is shown as the mean \pm SEM $(n=3)$ (Right). (D) HEK293T cells transfected with different plasmids were treated with $10 \mu \mathrm{M}$ MG132 for $8 \mathrm{~h}$ and then subjected to IP ubiquitination analyses using the indicated antibodies. (E) The shControl- and shPRMT5-HEK293T cells transfected with Flag-empty or Flag- 
PML-RAR $\alpha$ were treated with $10 \mu \mathrm{M}$ MG132 for $8 \mathrm{~h}$ and then subjected to IP ubiquitination analyses using the indicated antibodies. (F) The in situ binding between PML-RAR $\alpha$ and ubiquitin in NB4 cells was detected by Duolink PLA immunofluorescence using anti-PML-RAR $\alpha$ and anti-ubiquitin antibodies. Scale bar, $10 \mu \mathrm{m}$. Quantification results for the PLA dots indicating PML-RAR $\alpha$-ubiquitin interaction are shown as mean \pm SEM.

Figure 3. PRMT5 represses the RNF4-PML-RARa binding by interacting with RNF4. (A) The effect of PRMT5 on the interaction between PML-RAR $\alpha$ and RNF4 was examined by co-IP experiments in HEK293T cells transfected with the indicated plasmids. (B) Diagram of the in vitro interaction assay used for (C). HEK293T cells were transfected with Flag-PML-RAR $\alpha$ and His-SUMO2. SUMOylated PML-RAR $\alpha$ was immunoprecipitated with Flag beads, eluted by Flag peptide, and then purified by His-pulldown. Myc-PRMT5 was purified from transfected HEK293T cells by immunoprecipitation using anti-Myc antibodies. SUMOylated PML-RAR $\alpha$ was incubated with purified GST-RNF4 in the absence and presence of Myc-PRMT5. The interaction between RNF4 and SUMOylated PML-RAR $\alpha$ was assessed by immunoblotting. (C) The effect of PRMT5 on the RNF4-SUMOylated PML-RAR $\alpha$ interaction was examined by in vitro interaction assay. (D) The endogenous interaction between PRMT5 and RNF4 was confirmed in NB4 cells by co-IP experiments. (E) Duolink PLA assays were performed to confirm the in situ interaction between PRMT5 and RNF4 (red dots) in NB4 cells. Scale bar, $10 \mu \mathrm{m}$. Quantification results for the PLA dots indicating PRMT5-RNF4 interaction are shown as mean \pm SEM. (F) Schematic representation of full-length RNF4 and the RNF4 $\triangle$ RING mutation construct. The interactions between Myc-PRMT5 and HA-RNF4 full-length or $\triangle$ RING were detected by Co-IP assays. (G) Schematic representation of full-length PRMT5 and the PRMT5 
$\Delta \beta$-Barrel mutation construct. The interactions between HA-RNF4 and Myc-PRMT5 full-length or $\Delta \beta$-Barrel were detected by Co-IP assays.

Figure 4. RNF4 is methylated at R164 by PRMT5. (A) HA-tagged RNF4 was immunoprecipitated with the HA antibody from transfected HEK293T cells and methylation of RNF4 was detected using anti-SDMe-Arginine antibodies. (B) Mass spectrometric (MS) analysis of RNF4 methylation sites. HEK-293T cells were transfected with HA-RNF4. HA-RNF4 was immunopurified with anti-HA affinity beads followed by MS. (C) Immunoblotting of the methylation of RNF4 R164. HEK293T cells were transfected with the indicated plasmids for $48 \mathrm{~h}$. (D) Amino acid sequences from the indicated species were aligned using the ESPRIPT 3.0 website. Conserved sequences are highlighted. (E) Assay for in vitro methylation of RNF4 by PRMT5 using purified proteins. Left panel, Coomassie blue staining of GST-fused RNF4 wide-type (WT) or the RNF4 R164K mutant purified from E. coli. Middle panel, schematic representation of in vitro methylation assay. Right panel, purified MycPRMT5 proteins were incubated with purified GST-RNF4 WT or GST-RNF4 R164K mutant proteins. The reaction mixtures were separated by SDS-PAGE and analyzed by indicated antibodies. (F) Diagram of the in vitro ubiquitination assay used for (G). (G) HEK293T cells were transfected with Flag-PML-RAR $\alpha$ and His-SUMO2. Flag-tagged PML-RAR $\alpha$ was purified from transfected HEK293T cells by immunoprecipitation using anti-Flag antibodies, after which His-SUMO2-Flag-PML-RAR $\alpha$ was purified by $\mathrm{Ni}^{2+}$ pulldown and incubated with purified GST-RNF4 WT or GST-RNF4 R164K mutant proteins at $37{ }^{\circ} \mathrm{C}$ for $4 \mathrm{~h}$. The effect of R164 methylation on its E3 enzyme activity was analyzed by examination of the ubiquitination level of PML-RAR $\alpha$. 
Figure 5. RNF4 methylation inhibits PML-RAR $\alpha$ ubiquitination and degradation by blocking the RNF4-PML-RAR $\alpha$ interaction. (A) The interaction between PMLRAR $\alpha$ and RNF4 WT/R164K was examined by co-IP assay in HEK293T cells transfected with the indicated plasmids and treated with $\mathrm{As}_{2} \mathrm{O}_{3}(1 \mu \mathrm{M}, 16 \mathrm{~h})$. (B) The effect of RNF4 methylation on RNF-PML-RAR $\alpha$ interaction was examined by co-IP assay in HEK293T cells transfected with the indicated plasmids. (C) The effects of $\mathrm{As}_{2} \mathrm{O}_{3}$ on the PRMT5-PML-RAR $\alpha$ and RNF4-PML-RAR $\alpha$ interactions were analyzed by immunoblotting. HEK293T cells were transfected with the indicated plasmids and treated with $\mathrm{As}_{2} \mathrm{O}_{3}(1 \mu \mathrm{M})$ for $0 \mathrm{~h}, 0.5 \mathrm{~h}, 1 \mathrm{~h}$ or $2 \mathrm{~h}$. (D) Immunoblotting of the level of RNF4 methylation. HEK293T cells transfected with the indicated plasmids were treated with $\mathrm{As}_{2} \mathrm{O}_{3}(1 \mu \mathrm{M})$ for $0 \mathrm{~h}, 0.5 \mathrm{~h}, 1 \mathrm{~h}$ or $2 \mathrm{~h}$. (E) Representative images of NB4 cells immunostaining for PML (green), PRMT5 (red) and DAPI (blue). NB4 cells were treated with $\mathrm{As}_{2} \mathrm{O}_{3}(2 \mu \mathrm{M})$ for $0,0.5$ or $1.0 \mathrm{~h}$ to examine changes in the co-localization of PRMT5 and PML nuclear bodies. Scale bar, $10 \mu \mathrm{m}$. (F) IP assays of PML-RAR $\alpha$ ubiquitination. HEK293T cells were transfected with different plasmids in the presence or absence of $\mathrm{As}_{2} \mathrm{O}_{3}(1 \mu \mathrm{M}, 16 \mathrm{~h})$. (G) Immunoblotting of the abundance of PML-RAR $\alpha$. HEK293T cells were transfected with HA-RNF4 WT or HA-RNF4 R164K and FlagPML-RAR $\alpha$ in the presence or absence of $\mathrm{As}_{2} \mathrm{O}_{3}(1 \mu \mathrm{M}, 16 \mathrm{~h})$, after which they were treated with CHX (10 $\mu \mathrm{g} / \mathrm{mL})$. (H) Semi-quantification of PML-RAR $\alpha$ levels, with $\beta$ actin used as a loading control. Relative PML-RAR $\alpha$ levels at time 0 were set as 1 .

Figure 6. Inhibition of PRMT5 enhances PML-RARa degradation and the therapeutic efficacy of $\mathrm{As}_{2} \mathrm{O}_{3}$ in NB4 cells. (A) Cell viability analysis of NB4 cells with WT PRMT5 expression, PRMT5 knockdown or PRMT5 overexpression (OE) cultured in 96 -well plates $\left(1 \times 10^{4}\right.$ cells per well). Cell viability was measured with the 
CCK8 kit. (B) Colony formation of NB4 cells with WT PRMT5, PRMT5 knockdown or PRMT5 overexpression cultured in methylcellulose. The numbers of cell clones were counted. The PRMT5 protein level was confirmed by immunoblotting. (C) Effects of EPZ015666 (EPZ) $(5 \mu \mathrm{M}, 60 \mathrm{~h})$ or/and $\mathrm{As}_{2} \mathrm{O}_{3}(2 \mu \mathrm{M}, 2 \mathrm{~h})$ on endogenous PML-RAR $\alpha$ protein levels in NB4 cells were detected by Western blot assay. Quantification is shown as the mean \pm SEM $(n=3)$. (D) Experimental design for evaluating the growth, differentiation and apoptosis of NB4 cells with the indicated treatment. (E) Cell viability analyses of NB4 cells cultured in 96-well plates with $5 \mu \mathrm{M} \mathrm{EPZ}$, or $1 \mu \mathrm{M}$ $\mathrm{As}_{2} \mathrm{O}_{3}$, or $5 \mu \mathrm{M} E P Z$ in combination with $1 \mu \mathrm{M} \mathrm{As} \mathrm{O}_{2} \mathrm{O}_{3}$. Cell viability was measured with the CCK8 kit. (F) The proportions of apoptotic cells (left) and differentiated cells (right) were determined by flow cytometry. The results of A, B, C, E and F are shown as the mean $\pm \operatorname{SEM}(n=3)$. Statistical analysis was performed using Student's $t$-test, ${ }^{*} p$ $<0.05, * * p<0.01, * * * p<0.001, * * * * p<0.0001$.

\section{Figure 7. Combination of PRMT5 inhibitor EPZ015666 with As2 $\mathrm{O}_{3}$ impedes APL.}

(A) Experimental design for studying differentiation of BM of APL mice in vitro with the indicated treatment. (B) The proportion of differentiated cells was determined by flow cytometry. (C) The strategy for studying apoptosis and differentiation of human primary APL cells from APL patients with the indicated treatment. (D) The proportions of apoptotic cells (left) and differentiated cells (right) in primary human APL cells (APL patients \#6 and \#7) were determined by flow cytometry. The results of B and D are shown as the mean \pm SEM ( $n=3)$. Statistical analysis was performed using Student's $t$ test, ${ }^{*} p<0.05,{ }^{* *} p<0.01,{ }^{* * *} p<0.001$. (E) EPZ induced degradation of PML-RAR $\alpha$ in cells resistance to $\mathrm{As}_{2} \mathrm{O}_{3}$. HeLa cells transfected with the indicated plasmids were treated with $\mathrm{As}_{2} \mathrm{O}_{3}(1 \mu \mathrm{M}, 16 \mathrm{~h})$ or EPZ $(5 \mu \mathrm{M}, 60 \mathrm{~h})$ and the protein abundance of 
PML-RAR $\alpha$ was detected by Western blotting. (F) Determination of PML-RAR $\alpha$ protein degradation pathway by EPZ. HeLa cells transfected with the indicated plasmids were treated with $\mathrm{As}_{2} \mathrm{O}_{3}(1 \mu \mathrm{M}, 16 \mathrm{~h})$ or EPZ $(10 \mu \mathrm{M}, 20 \mathrm{~h})$, and $10 \mu \mathrm{M}$ MG132 was added to culture for an additional $12 \mathrm{~h}$. And then the abundance of PMLRAR $\alpha$ protein was examined by Western blot assay.

Figure 8. A working model for regulation of PML-RARa stability and APL pathogenesis by PRMT5. PRMT5 associates with and stabilizes PML-RAR $\alpha$ to promote APL pathogenesis by methylating RNF4 at R164. PRMT5 inhibitor EPZ015666 in combination with $\mathrm{As}_{2} \mathrm{O}_{3}$ increases APL cells apoptosis and differentiation by disrupting the PRMT5/RNF4 interaction and enhancing the RNF4/PML-RAR $\alpha$ interaction, thus suppressing APL progression. 
Figure 1

A

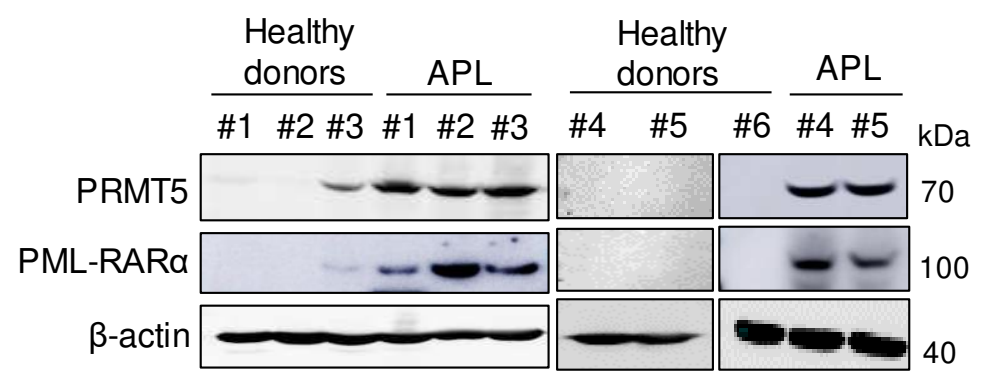

B

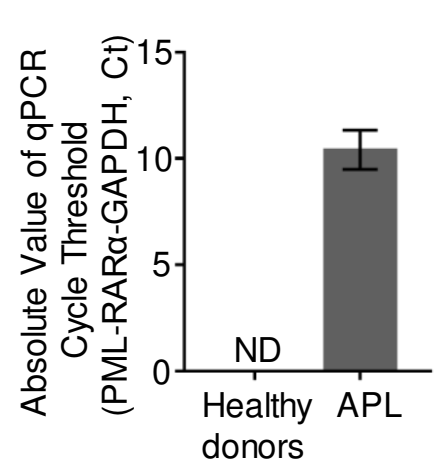

C

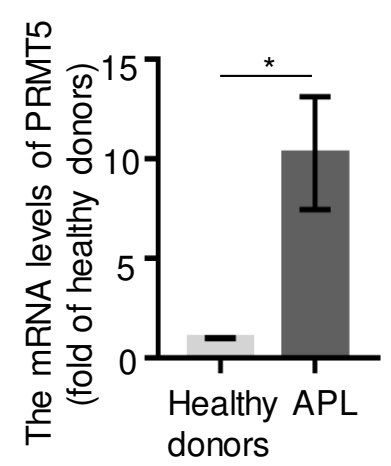

D

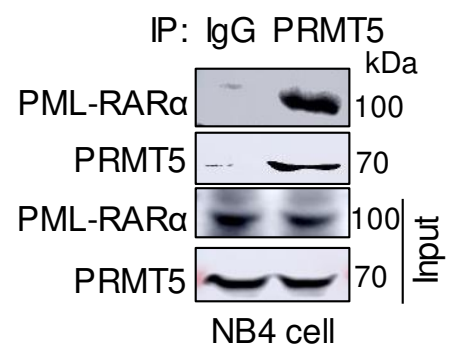

E PRMT5

PML-RARa

DAPI

Merge
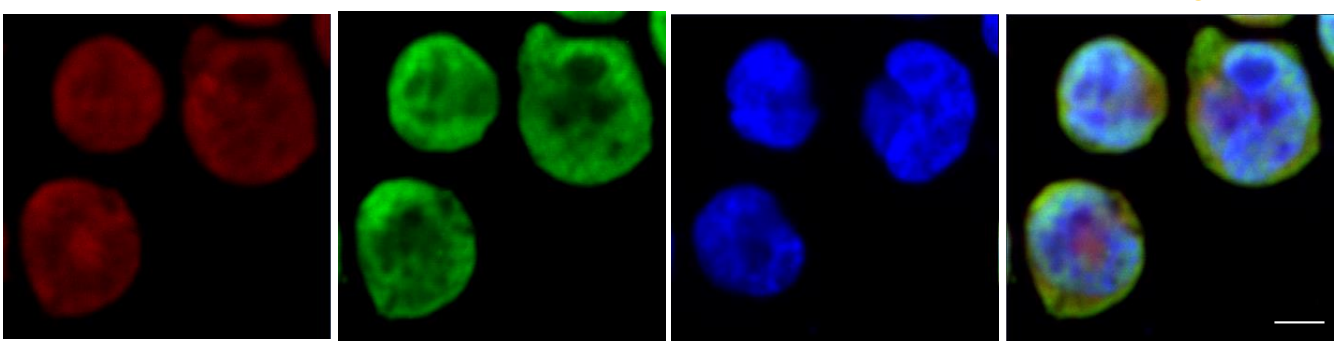

NB4 cell

$\mathbf{F}$ Duolink PLA assay

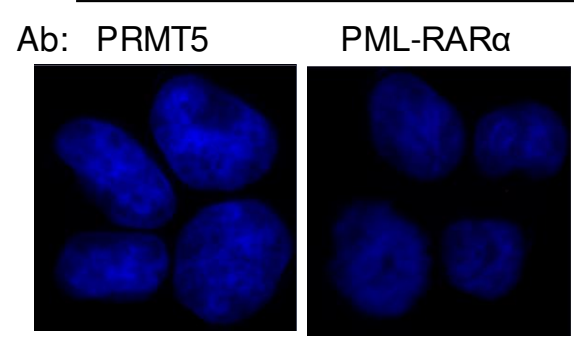

NB4 cell
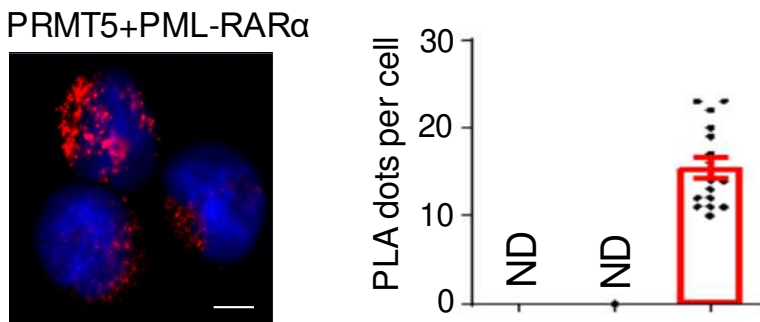

anti-PRMT5 +-+ anti-PML-RARa $\quad-\quad+\quad+$ 
Figure 2

A

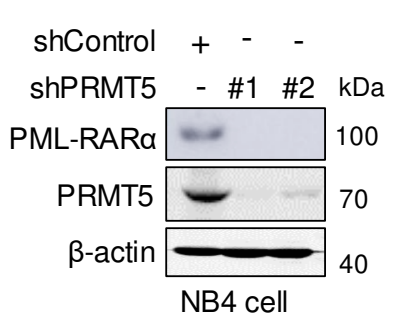

C

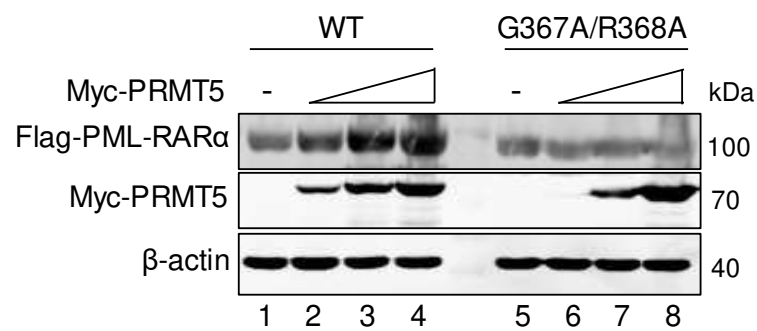

B

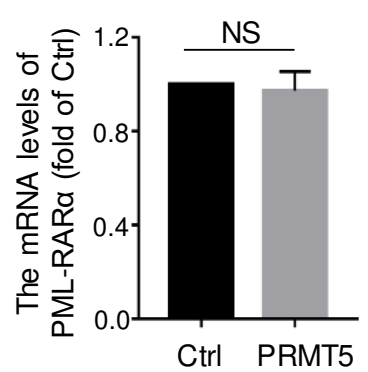

D

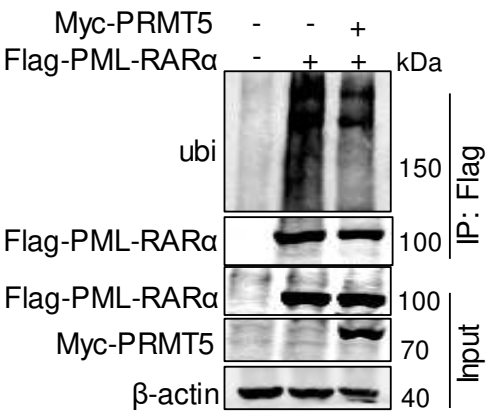

$\mathbf{F}$

Duolink PLA: PML-RARa

and ubiquitin interaction

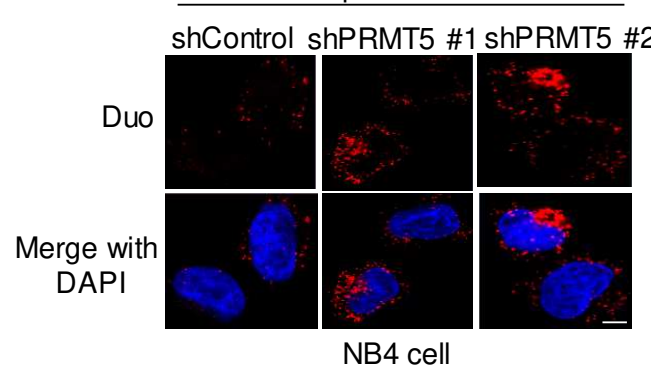

E

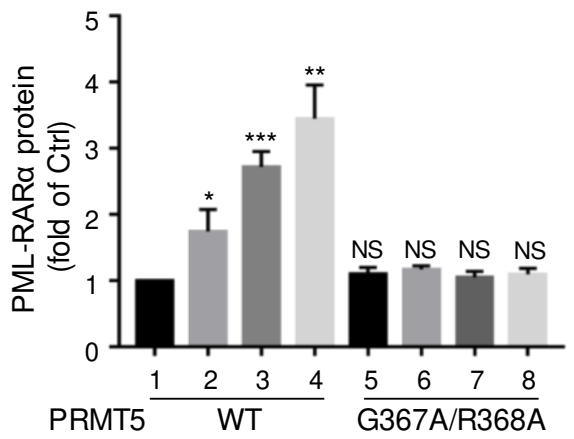

shControl + + - -

ShPRMT5 - - \#1 \#2
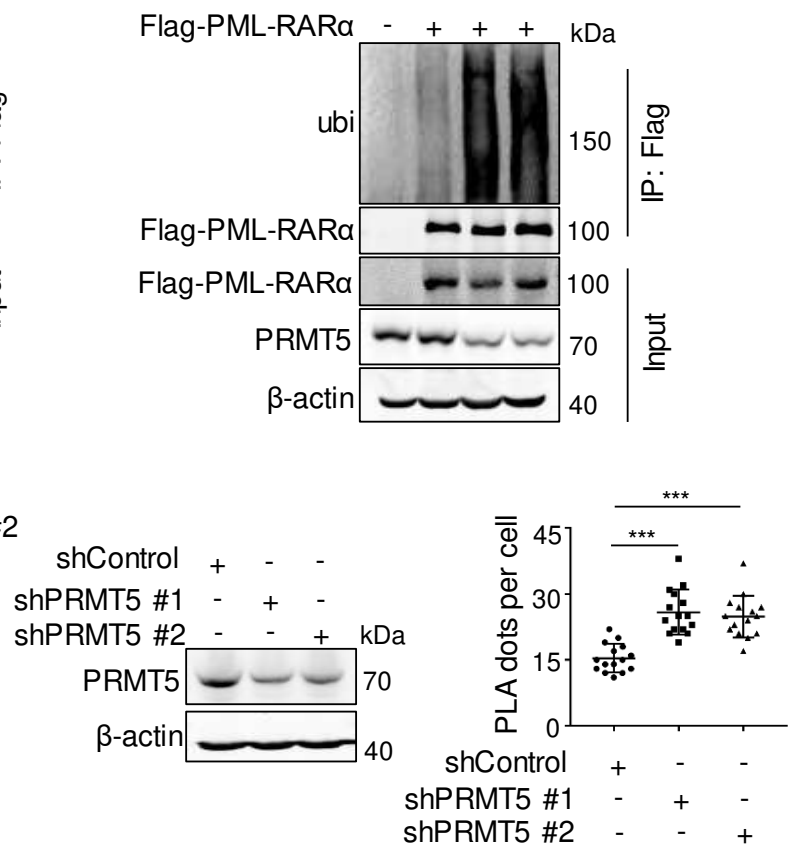
Figure 3

A

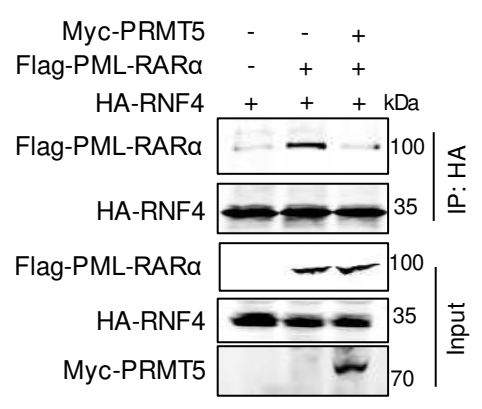

B Flag-PML-RARa and His-SUMO2 co-transfection

$$
\text { IP: Flag }
$$

Flag-PML-RARo

His-pull down

SUMOylated PML-RAR $\alpha$

$\stackrel{+}{\stackrel{+}{-}}$

from E.coli Myc-PRMT5

In vitro interaction assay

E

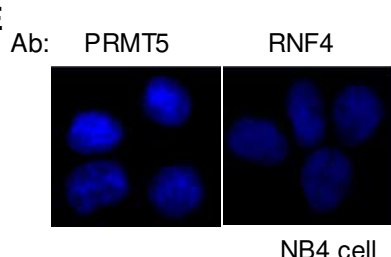

C

SUMOylated PML-RARa ++

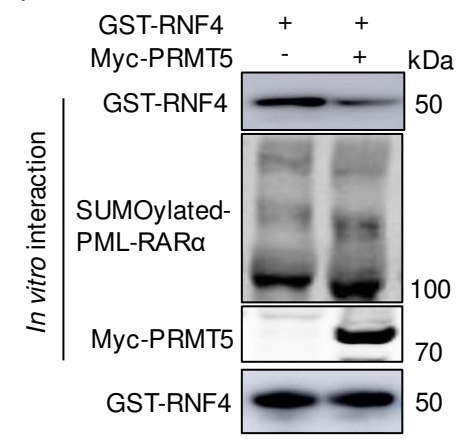

D

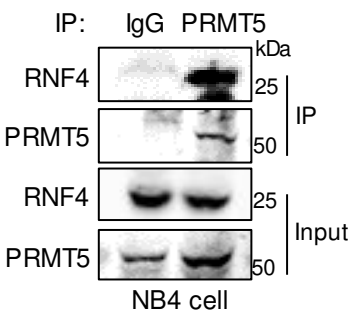

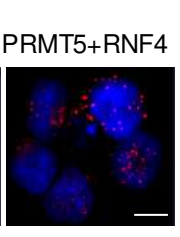

B4 cell

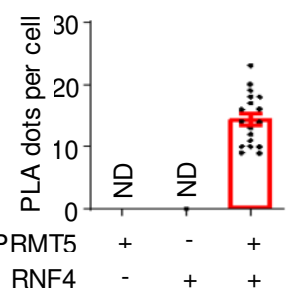

RNF4 FL

HA-RNF4 vector FL $\triangle$ RING

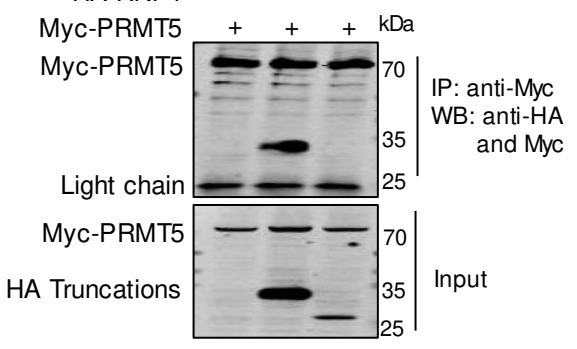

$4^{\text {PRMT5 binding }}$
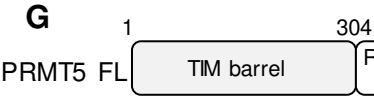

RNF4 binding

$\Delta \beta$-Barrel \begin{tabular}{|l|l|} 
TIM barrel & $\begin{array}{c}\text { Rossmann } \\
\text { fold }\end{array}$ \\
\hline
\end{tabular}

Myc-PRMT5 vector FL $\Delta \beta$-Barrel

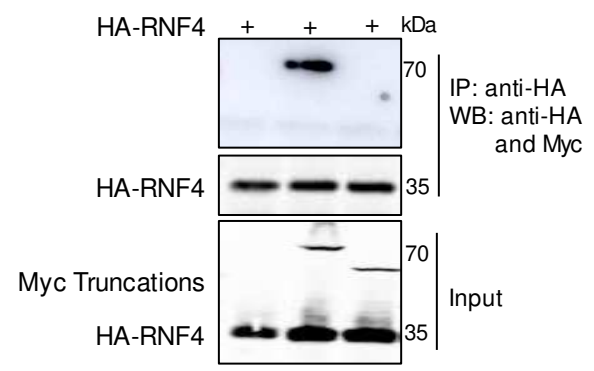


Figure 4

A B

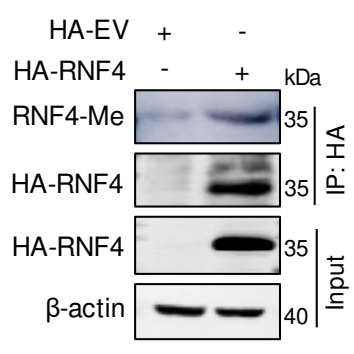

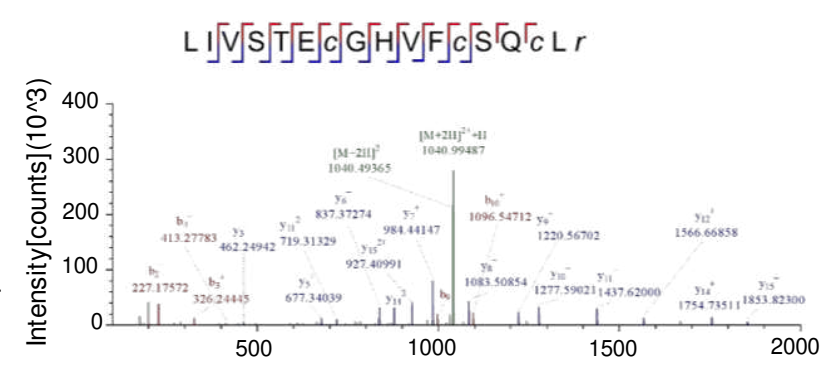

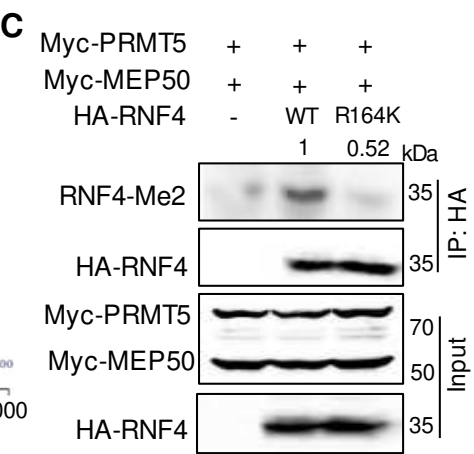

D R164

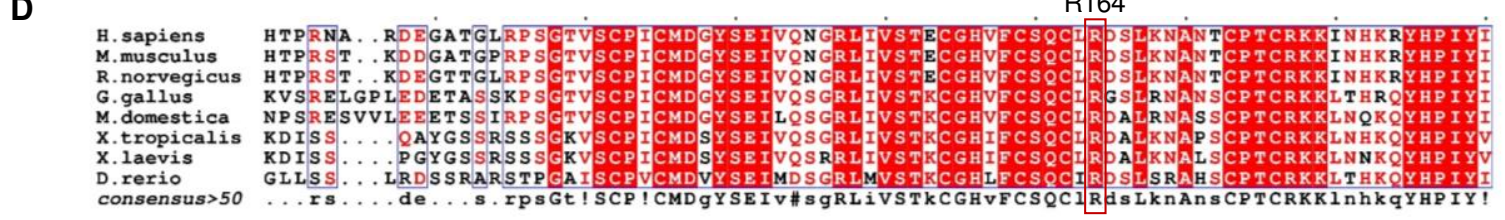

E

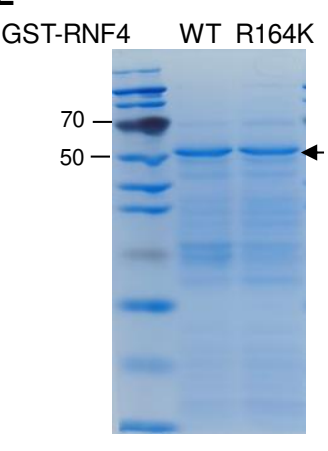

$\mathbf{F}$

Flag-PML-RARa and His-SUMO2 co-transfection

$$
\downarrow \text { IP: Flag }
$$

Flag-PML-RARa

$$
\downarrow \text { His-pull down }
$$

SUMOylated PML-RAR $\alpha$
GST-RNF4 WT/R164K from E.coli

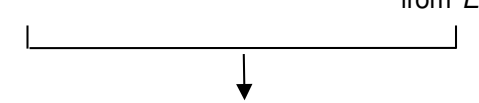

In vitro ubiquitination assay
S-(5'-Adenosyl)-Lmethionine iodide Purified RNF4

Purified WT/R164K

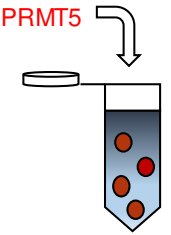

Supplements

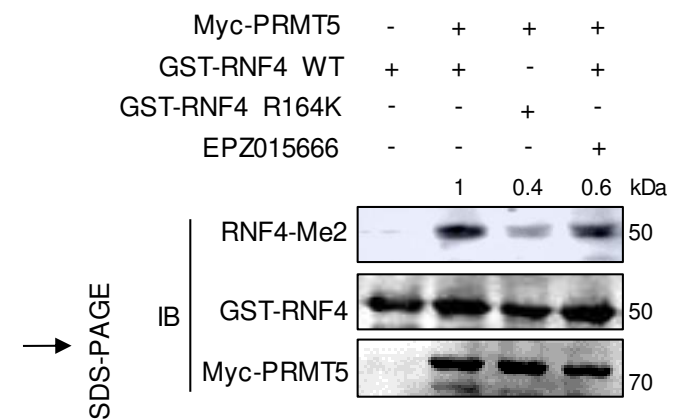

G

E1

$\mathrm{E} 2+++$

ubiquitin +++

SUMOylated PML-RARa + + +

GST-RNF4 - WT R164K

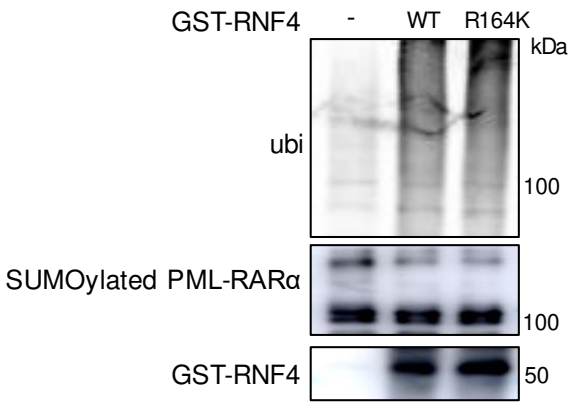


Figure 5

A

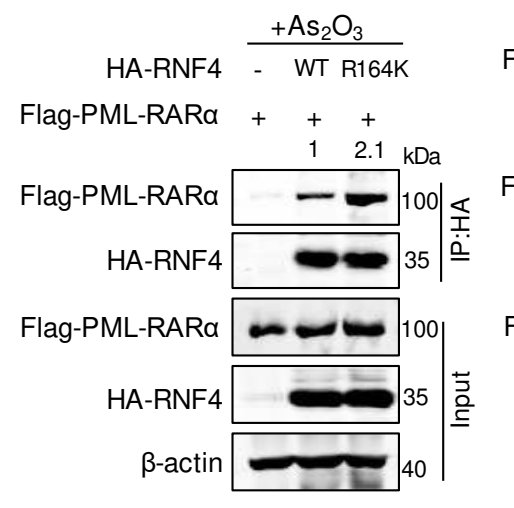

D

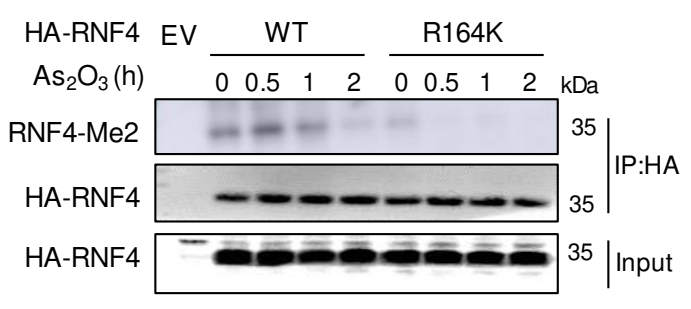

$\mathbf{F}$

$$
\text { HA-RNF4 } \frac{-\mathrm{As}_{2} \mathrm{O}_{3}}{-} \frac{+\mathrm{As}_{2} \mathrm{O}_{3}}{- \text { WTR164K }}-\frac{\text { WT R164K }}{-\mathrm{W}}
$$

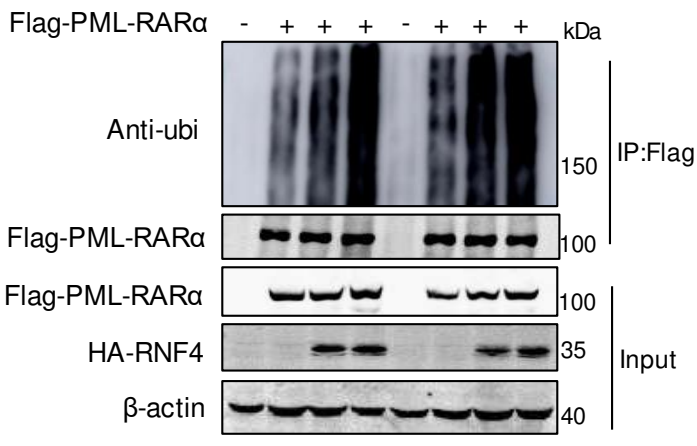

G

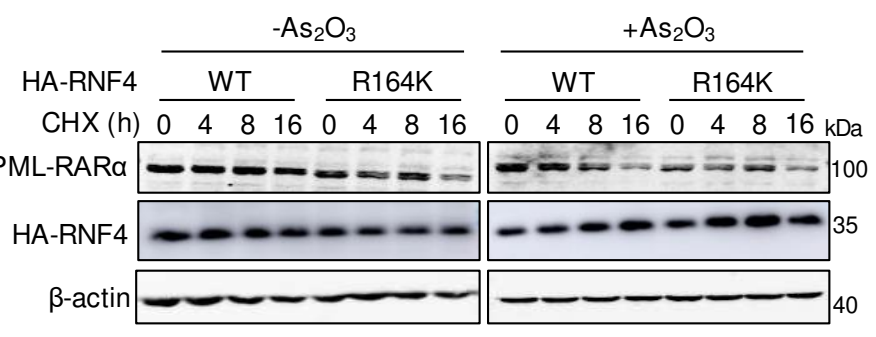

C

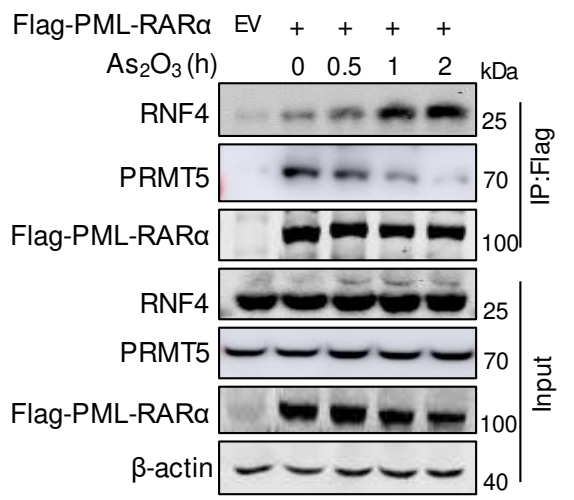

E
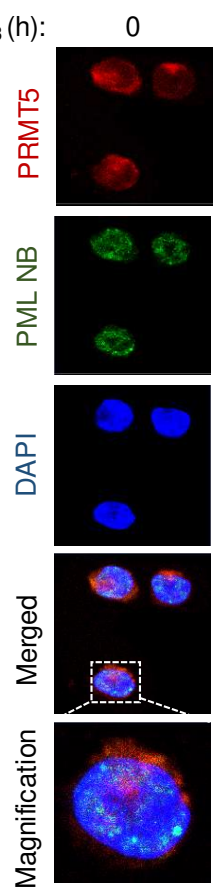

NB4 cell
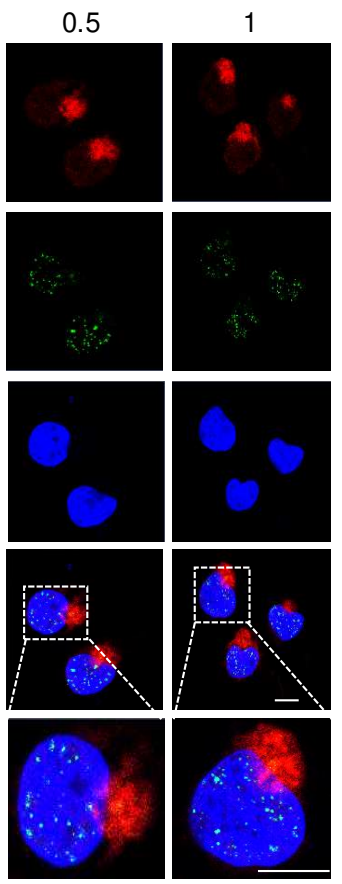

$\rightarrow$ HA-RNF4 WT

- HA-RNF4 R164K

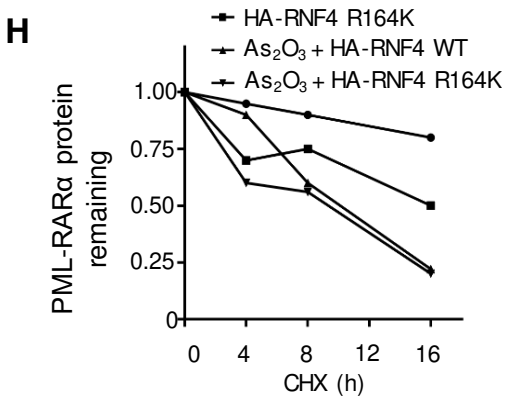


Figure 6

A

NB4 cell

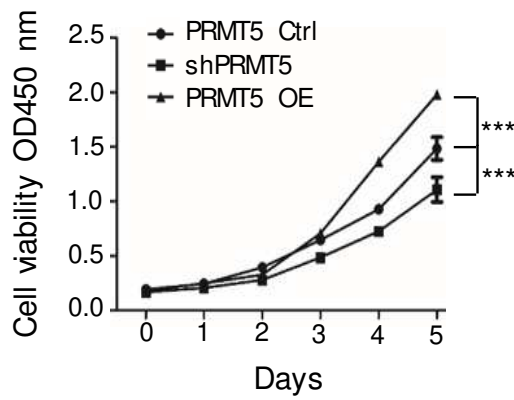

C

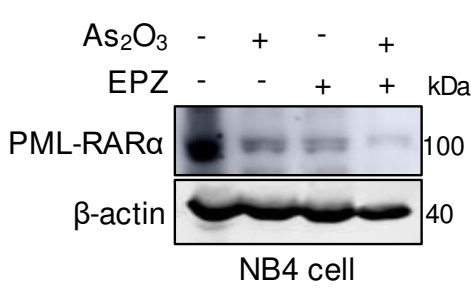

D

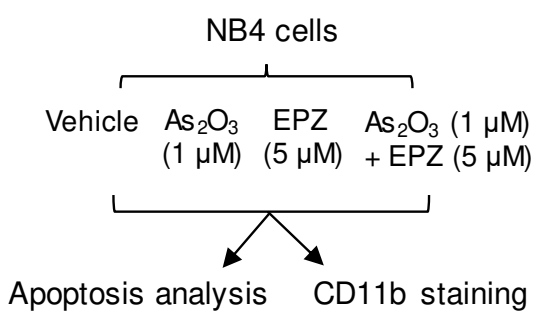

F

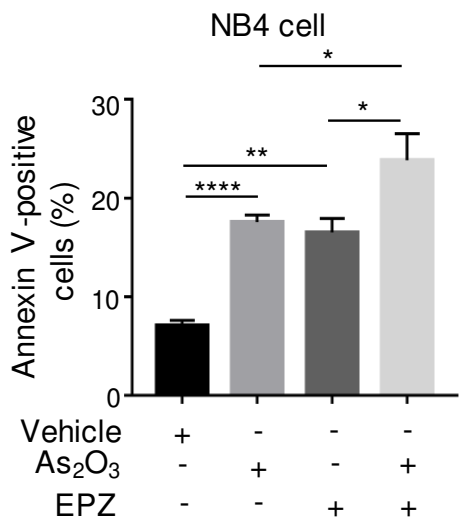

B

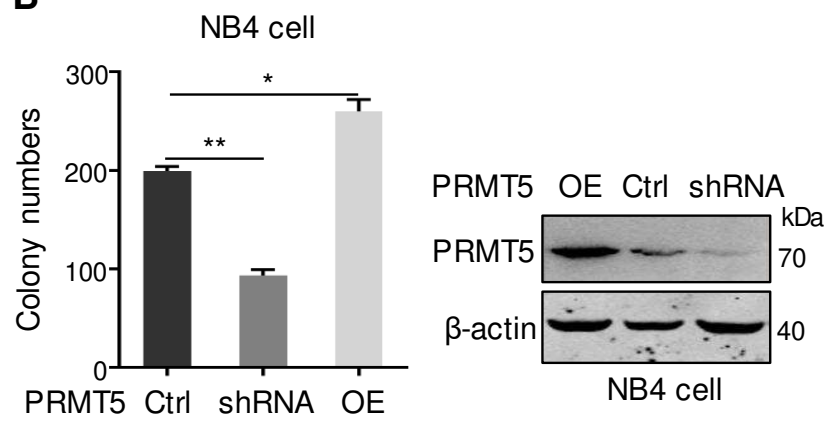

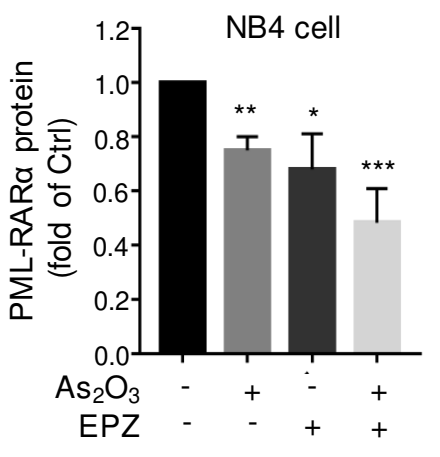

E

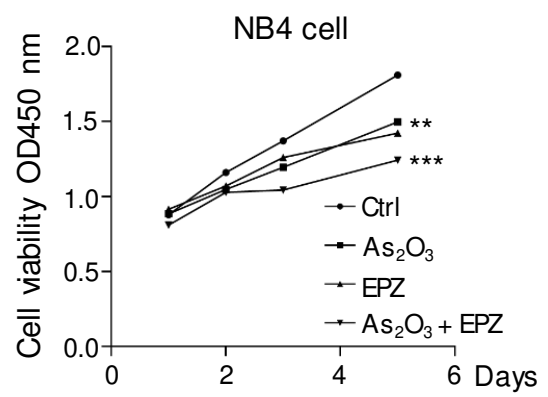

NB4 cell

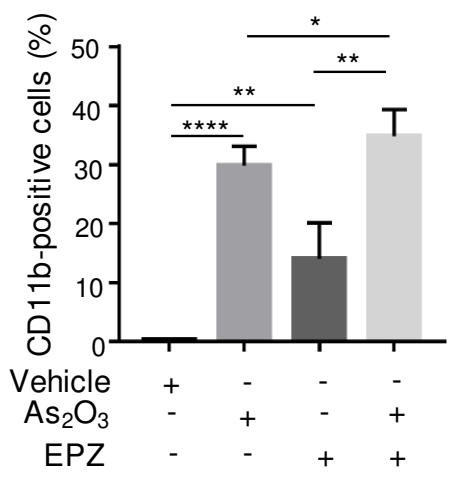


Figure 7

A

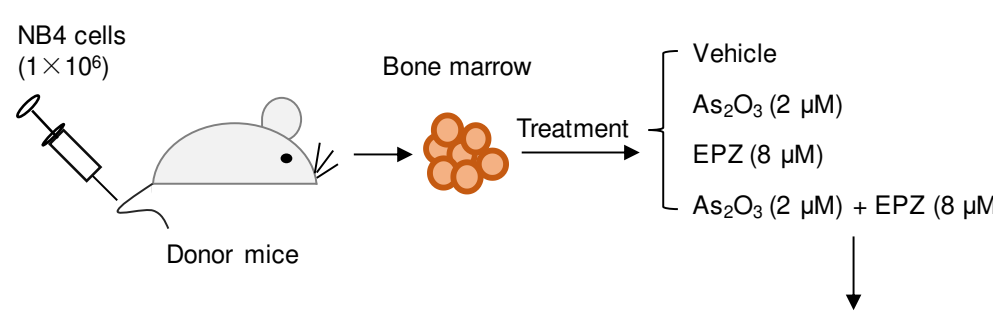

CD11b staining
B

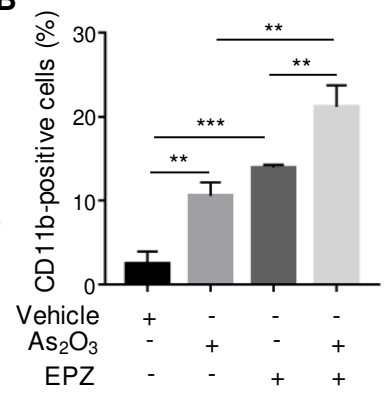

C

D APL patient \#6
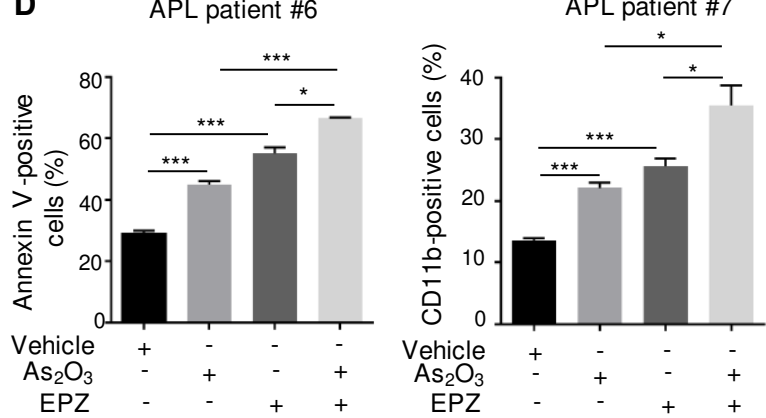

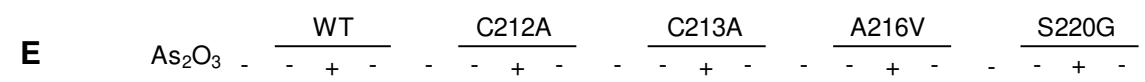

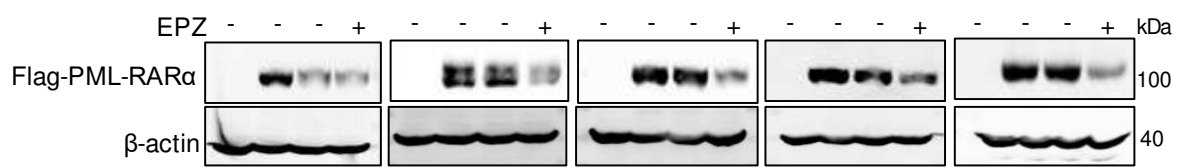

F

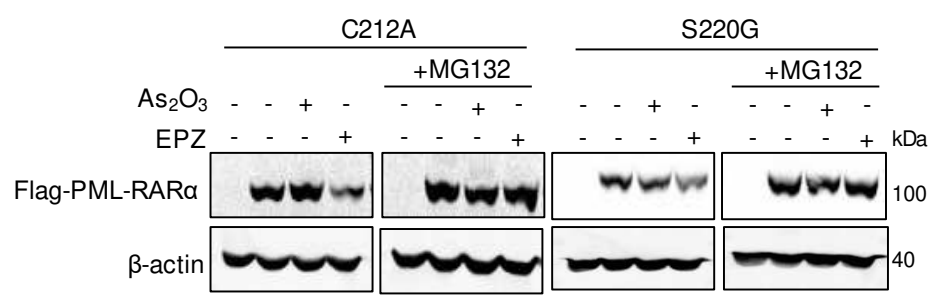


Figure 8

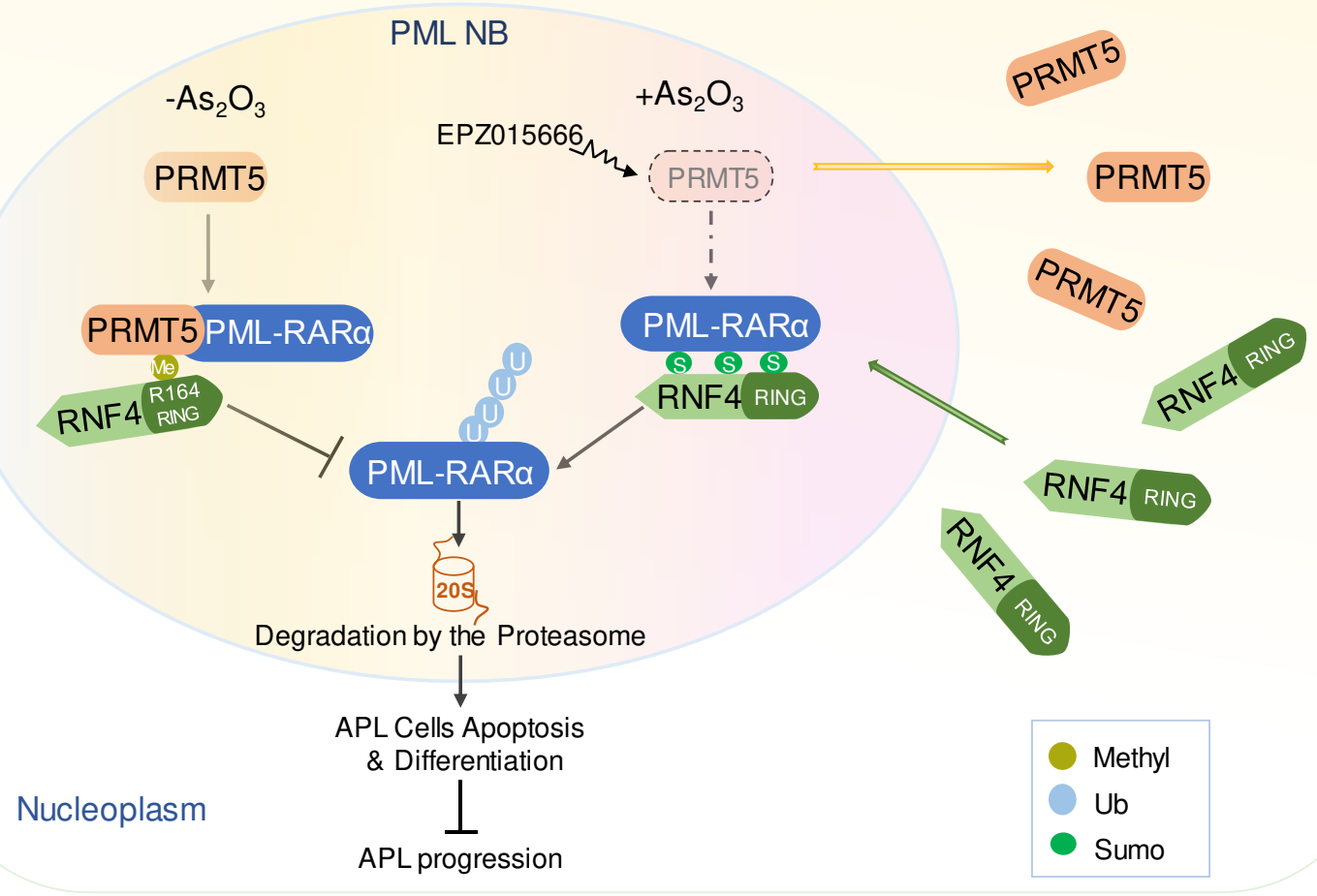




\section{Supplementary Files}

This is a list of supplementary files associated with this preprint. Click to download.

- Supplementaryinformation.docx 